\title{
Formulation of insulin-loaded nanoparticles by using double emulsion/solvent evaporation method and microfluidics/salting out technique
}

\author{
Gurjit Kaur Pannu ${ }^{1}$, Ahmed El-Safy ${ }^{2}$, Samuel Girgis ${ }^{3}$ and Ahmed Faheem ${ }^{4}$ \\ ${ }^{1,2,3,4}$ Edinburgh Building Chester Rd, SR1 3SD \\ ${ }^{1} 0447425215850$, bg90mw@student.sunderland.ac.uk \\ ${ }^{2} 00447438905841$,a.elsafy177@gmail.com \\ ${ }^{3} 00447404780179$, bg96CD@ student.sunderland.ac.uk \\ ${ }^{4} 00447715433350$, Ahmed.Faheem@sunderland.ac.uk
}

\section{Abstract}

The aim of this study was to investigate the effect of nanoparticles formulation techniques which include double emulsion/solvent evaporation and microfluidics/salting out techniques on the physicochemical characteristics of polymeric insulin-loaded nanoparticles. Double emulsion/solvent evaporation and microfluidics/salting out techniques were utilized to formulate insulin-loaded nanoparticles prepared from poly (lactic-co-glycolic acid), polyvinylpyrrolidone and poly (1-vinylpyrrolidone-co-vinyl acetate). Formulation parameter such as type of polymer and physicochemical properties which include particle size, zeta potential, surface analysis, entrapment efficiency, in vitro release study and stability of nanoparticles formulated by both of the techniques were investigated. Insulin-loaded nanoparticles formulated by using both of the techniques were negatively charged and spherical with mean size ranging from 270-390 nm. Entrapment efficiency of insulin-loaded nanoparticles formulated by double emulsion/solvent evaporation technique was higher than microfluidics/salting out technique. Insulin-loaded nanoparticles of double emulsion/solvent evaporation method showed higher initial release during insulin in vitro release study when compared to nanoparticles formulated by microfluidic/salting out technique. FTIR analysis confirmed the compatibility between polymers used and insulinloaded nanoparticles. DSC thermograms showed insulin-loaded nanoparticles formulated by both of the techniques had glass transition temperature at about $50^{\circ} \mathrm{C}$. Thus, microfluidics/salting out technique is effective to determine the particle size, zeta potential, surface analysis and rate of release. On the other hand, double emulsion/solvent evaporation technique had shown better insulin entrapment efficiency.

Key words: microfluidics, emulsion, salting out, Insulin

Corresponding Author: Samuel Girgis

\section{Introduction}

Diabetes is one of the main causes of human death in the world, whereby 150 million people are affected and the statistics possibly will increase to about 300 million people by the year of 2025 (Saravanan et al., 2017). Insulin is one of the main treatments for diabetes and is usually taken by diabetic patients via subcutaneous route for better management of diabetes. The bioavailability by subcutaneous route is $100 \%$ due to its faster absorption rate (Chen et al., 2011). Nevertheless, insulin treatment given subcutaneously generally cause poor patient compliance and pain because administration of insulin by diabetic patients is 
needed every time before meals. On the other hand, administration of insulin orally is limited in the human body due to the early digestion of insulin in the stomach where the environment is acidic (Gupta and Mohanty, 2017). Therefore, nanoparticles are designed in order to overcome these complications as delivery of insulin by using nanoparticles have shown promising results in the biomedicine field whereby drug absorption in vivo is increased after oral administration (Chen et al., 2011).

To ensure an effective delivery of insulin, insulin-loaded nanoparticles must be biodegradable, stable, non-toxic, non-inflammatory, non-immunogenic, non-thrombogenic and can be removed via reticuloendothelial system. Nanoparticulate system must be small, ranging from 2 to $1000 \mathrm{~nm}$, which is appropriate for numerous molecules such as nucleic acids, small drugs, proteins, and vaccines for therapeutic various purposes (Sharma et al., 2015). By using insulin-loaded nanoparticles, a specific site in the body can be targeted which is an advantage of using nanoparticles to deliver insulin. Moreover, another advantage of insulin-loaded nanoparticles is that controlled release of insulin can be achieved as sustained release of insulin is maintained over prolonged time periods with reduced side effects. Thus, this is a desirable characteristic for a nanoparticle because frequency of administration can be reduced in the treatment of diabetes (Gupta and Mohanty, 2017).

For effective delivery of insulin, biodegradable polymers are often utilized to formulate nanoparticles which are functionally stable and suitable to encapsulate smaller proteins besides formulating nanoparticles with improved pharmacokinetic profiles (Haggag et al., 2016). Numerous combinations of polymers can be used to formulate the sustained release of insulin and its improved uptake and bioavailability (Sharma et al., 2015). Therefore, many studies are conducted to design insulin-loaded polymeric nanoparticles.

In this study, double emulsion/solvent evaporation and microfluidics/salting out techniques were used to formulate insulin-loaded nanoparticles. In double emulsion/solvent evaporation technique, organic phase of polymers in dichloromethane (DCM) and aqueous phase of insulin in poly (vinyl alcohol) (PVA) are prepared which then undergo primary and secondary emulsification by homogenization. PVA is a stabilizer which is usually used to stabilize the emulsion system by prevention of the phases separation or division and also by sustaining the physicochemical state of a dispersion of more than two immiscible phases (Rizkalla et al., 2006). In primary emulsification, the inner aqueous phase which contains insulin is dispersed in the organic phase with the polymer in DCM. In secondary emulsification, the primary emulsion is then dispersed into the outer aqueous phase of hydrophilic emulsifier which is PVA. In microfluidics/salting out technique, the microfluidics device used has two inlets, one for the aqueous phase containing insulin in PVA and another one for organic phase containing polymer in acetonitrile. The aqueous phase is usually supplied into two channels and the organic phase is introduced to the channel in the center as the disperse phase. Salting out is a novel technique combined with microfluidics technique in order to form precipitation of nanoparticles.

In the present study, three different insulin-loaded nanoparticles are formulated; PLGA nanoparticles, PLGA + 5\% PVP nanoparticles and PLGA + 5\% PVP + 5\% PVP co-polymer nanoparticles, with double emulsion/solvent evaporation and microfluidics/salting out techniques. The physicochemical characteristics of insulin-loaded nanoparticles formulated which include particle size, zeta potential, surface analysis, stability, in vitro release profiles and encapsulation efficiency were investigated. The aim of this study was to investigate the effect of nanoparticles formulation techniques which include double emulsion/solvent evaporation and microfluidics/salting out techniques on the physicochemical characteristics of polymeric insulinloaded nanoparticles. 


\section{Materials and Methods}

\subsection{Materials}

Poly (lactic-co-glycolic acid (PLGA; Resomer ${ }^{\circledR}$ RG $503 \mathrm{H}$ ) with a glycolide:lactide ratio of 50:50 (MW 24-38 kDa), Polyvinylpyrrolidone (PVP; MW 40 kDa) and poly (1vinylpyrrolidone-co-vinyl acetate) (PVP co-polymer; MW $50 \mathrm{kDa}$ ) were obtained from Sigma-

Aldrich Co. (St. Louis, USA). Human recombinant insulin, poly (vinyl alcohol) (PVA, MW $1323 \mathrm{kDa} ; 87-89 \%$ hydrolyzed) and phosphate buffered saline (PBS) were purchased from Sigma

Chemical Co. (St. Louis, USA). BCA protein assay kit was purchased from Pierce ${ }^{\mathrm{TM}}$ (Rockford,

IL). di-Sodium tetraborate anhydrous was purchased from Fisher Scientific, UK. Dichloromethane used was of HPLC grade and Pierce® Acetonitrile (Thermo Scientific, UK) used was of LC-MS grade. Distilled water was used throughout the study.

\subsection{Preparation of insulin loaded nanoparticles}

\subsubsection{Double emulsion/solvent evaporation technique}

Insulin loaded nanoparticles with different formulations shown in Table 1 were prepared by using double emulsion/solvent evaporation method as explained in Figure 1. Each formulation was prepared in triplicates to decrease errors. For instance, G1, G2 and G3 are PLGA nanoparticles, G4, G5 and G6 are PLGA + 5\% PVP nanoparticles and G7, G8 and G9 are PLGA $+5 \%$ PVP + 5\% PVP co-polymer nanoparticles. For primary emulsion, $10 \mathrm{~mL}$ of $2.5 \%$ PVA stock solution was prepared by weighing $0.25 \mathrm{~g}$ of PVA and $10 \mathrm{~mL}$ of water was added and the solution was then stirred until it was completely dissolved. On the other hand, $200 \mathrm{~mL}$ of $1.25 \%$ PVA stock solution for secondary emulsion was prepared whereby $2.5 \mathrm{~g}$ of PVA was weighed and

$200 \mathrm{~mL}$ of water was added and stirred until the solution was completely dissolved. Organic phase was prepared by dissolving the amount of polymers as shown in Table 1 for each formulation, in $6 \mathrm{~mL}$ of dichloromethane (DCM) and stirred until dissolved completely. To prepare the internal aqueous phase with insulin, firstly, amount of insulin as shown in Table 1 was weighed in Eppendorf tube for each formulation. As insulin has low solubility in neutral $\mathrm{pH}, 0.5 \mathrm{~mL}$ of $0.1 \mathrm{M}$ hydrochloric acid $(\mathrm{HCl})$ was added in the tube to solubilize insulin and $0.5 \mathrm{~mL} 2.5 \%$ of PVA was added in the Eppendorf tube. A Whirlimixer (Fisons Scientific Apparatus, England) was used to completely dissolve the insulin added in the tubes.

For homogenization of primary emulsion (w/o), the internal aqueous phase with insulin was added dropwise to the organic phase prepared, which contain different composition of polymers, by using a homogenizer (Stuart ${ }^{\circledR}$ Homogenizer SHM2, UK) at 6,000 rpm for 2 minutes on ice. The primary emulsion obtained was then added dropwise to the $50 \mathrm{~mL}$ of $1.25 \%$ PVA solution which acts as the external phase, by using a different homogenizer (Silverson L5M Homogeniser, Silverson Machines, England) at 10,000rpm for 6 minutes on ice to obtain a secondary emulsion $(\mathrm{w} / \mathrm{o} / \mathrm{w})$. The secondary emulsion obtained was stirred for 24 hours in order to evaporate DCM and avoid the formation of pores on the surface of nanoparticles. After 24 hours, nanoparticles were transferred into centrifuge tubes and centrifuged at 10,000 rpm for about 25 minutes by using centrifugation (MSE Mistral 1000, UK). Nanoparticles were washed for 3 times with distilled water. Nanoparticles obtained from the final wash were divided into two; whereby one of it was in liquid form and the other was kept at $-80^{\circ} \mathrm{C}$ for 2 hours and then lyophilized (VirTis ${ }^{\circledR}$ BenchTop ${ }^{\mathrm{TM}} \mathrm{K}$ Series Freeze Dryer, UK) for 48 hours. After lyophilization, the nanoparticles were stored in a cupboard at room temperature. 

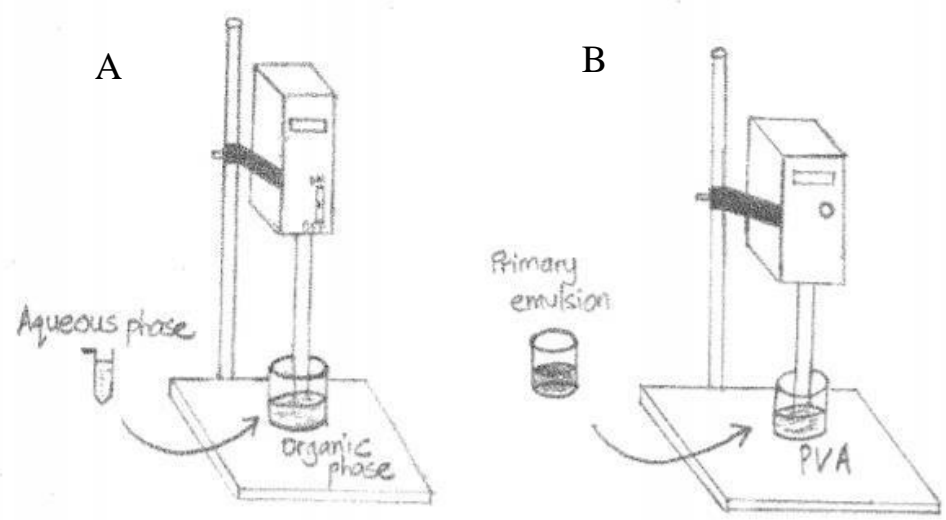

$\mathrm{C}$

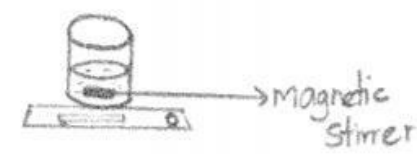

Figure 1: Double emulsion/solvent evaporation method; (A) Primary homogenization: aqueous phase is dispersed into organic phase; (B) Secondary homogenization: Primary emulsion is dispersed into outer aqueous phase containing PVA; (C) Solvent evaporation:

Secondary emulsion is stirred overnight

Table 1: Formulation identification with composition $(\mathrm{mg})$ of polymers and insulin in each type of nanoparticles for double emulsion/solvent evaporation technique

\begin{tabular}{|c|c|c|c|c|c|}
\hline \multirow{3}{*}{$\begin{array}{c}\text { Type of } \\
\text { nanoparticles }\end{array}$} & \multirow[t]{3}{*}{ Formulation ID } & \multicolumn{4}{|c|}{ Composition (mg) } \\
\hline & & \multicolumn{3}{|c|}{ Polymers } & \multirow[t]{2}{*}{ Insulin } \\
\hline & & PLGA & PVP & $\begin{array}{c}\text { PVP } \\
\text { copolymer }\end{array}$ & \\
\hline \multirow{3}{*}{ PLGA } & G1 & 200 & & & 4 \\
\hline & G2 & 200 & & & 4 \\
\hline & G3 & 200 & & & 4 \\
\hline \multirow{3}{*}{$\begin{array}{c}\text { PLGA + 5\% } \\
\text { PVP }\end{array}$} & G4 & 190 & 10 & & 4 \\
\hline & G5 & 190 & 10 & & 4 \\
\hline & G6 & 190 & 10 & & 4 \\
\hline \multirow{3}{*}{$\begin{array}{c}\text { PLGA + 5\% } \\
\text { PVP + 5\% PVP } \\
\text { copolymer }\end{array}$} & G7 & 180 & 10 & 10 & 4 \\
\hline & G8 & 180 & 10 & 10 & 4 \\
\hline & G9 & 180 & 10 & 10 & 4 \\
\hline
\end{tabular}

(shaded boxes represent the absence of the polymer in the particular formulation)

\subsubsection{Microfluidics technique by NanoAssemblr ${ }^{\mathrm{TM}}$}

Insulin loaded nanoparticles with different formulations shown in Table 2 were prepared by using microfluidics technique by using NanoAssembler ${ }^{\mathrm{TM}}$ as explained in Figure 2. Each formulation was prepared in triplicates to decrease errors. For instance, G1M, G2M and G3M are PLGA nanoparticles, G4M, G5M and G6M are PLGA + 5\% PVP nanoparticles and 
G7M, G8M and G9M are PLGA + 5\% PVP + 5\% PVP co-polymer nanoparticles. For microfluidics technique, organic phase and aqueous phase which consists of polymer and insulin respectively, were prepared. Organic phase was prepared by dissolving the amount of polymers shown in Table 2 for each formulation, in $4 \mathrm{~mL}$ of acetonitrile and stirred until dissolved completely. The aqueous phase was prepared by dissolving insulin as shown in Table 2 for each formulation in $0.5 \mathrm{~mL}$ of

$0.1 \mathrm{M} \mathrm{HCl}$ and $0.5 \mathrm{~mL}$ of $1.25 \%$ PVA solution in Eppendorf tubes. A Whirlimixer (Fisons Scientific Apparatus, England) was used to dissolve the insulin completely for about 2 minutes.

Emulsion of nanoparticles was produced for each formulation by using NanoAssembler ${ }^{\mathrm{TM}}$ (Precision Nanosystems, Vancouver, BC) when the organic phase and aqueous phase were supplied to two different inlets in the equipment with the ratio of $4: 1$ respectively and flow rate of $12 \mathrm{~mL} / \mathrm{min}$. Salting out of nanoparticles was performed by adding salt which is di-Sodium tetraborate anhydrous (Fisher Scientific, UK) with the amount of $100 \mathrm{mg}$ for each formulation. The nanoparticles with the salt added were left for 24 hours at room temperature. After 24 hours, nanoparticles were transferred into centrifuge tubes and centrifuged at 10,000 rpm for about 25 minutes by using centrifugation (MSE Mistral 1000, UK) and washed once with distilled water. The final product of nanoparticles was divided into two; whereby one of it was in suspension form and the other part was kept at $-80^{\circ} \mathrm{C}$ for 2 hours and then lyophilized (VirTis ${ }^{\circledR}$ BenchTop ${ }^{\mathrm{TM}}$ K Series Freeze Dryer, UK) for 48 hours. After lyophilization, the nanoparticles were stored in a cupboard at room temperature.

Table 2: Formulation identification with composition $(\mathrm{mg})$ of polymers and insulin in each type of nanoparticles for microfluidics/salting out technique

\begin{tabular}{|c|c|c|c|c|c|}
\hline \multirow{3}{*}{$\begin{array}{c}\text { Type of } \\
\text { nanoparticles }\end{array}$} & \multirow{3}{*}{$\begin{array}{l}\text { Formulation } \\
\text { ID }\end{array}$} & \multicolumn{4}{|c|}{ Composition (mg) } \\
\hline & & \multicolumn{3}{|c|}{ Polymers } & \multirow[t]{2}{*}{ Insulin } \\
\hline & & PLGA & PVP & $\begin{array}{c}\text { PVP } \\
\text { copolymer }\end{array}$ & \\
\hline \multirow{3}{*}{ PLGA } & G1M & 200 & & & 4 \\
\hline & G2M & 200 & & & 4 \\
\hline & G3M & 200 & & & 4 \\
\hline \multirow{3}{*}{$\begin{array}{c}\text { PLGA + 5\% } \\
\text { PVP }\end{array}$} & G4M & 190 & 10 & & 4 \\
\hline & G5M & 190 & 10 & & 4 \\
\hline & G6M & 190 & 10 & & 4 \\
\hline \multirow{3}{*}{$\begin{array}{c}\text { PLGA + 5\% } \\
\text { PVP + 5\% } \\
\text { PVP } \\
\text { copolymer }\end{array}$} & G7M & 180 & 10 & 10 & 4 \\
\hline & G8M & 180 & 10 & 10 & 4 \\
\hline & G9M & 180 & 10 & 10 & 4 \\
\hline
\end{tabular}

(shaded boxes represent the absence of the polymer in the particular formulation) Dispersed phase 


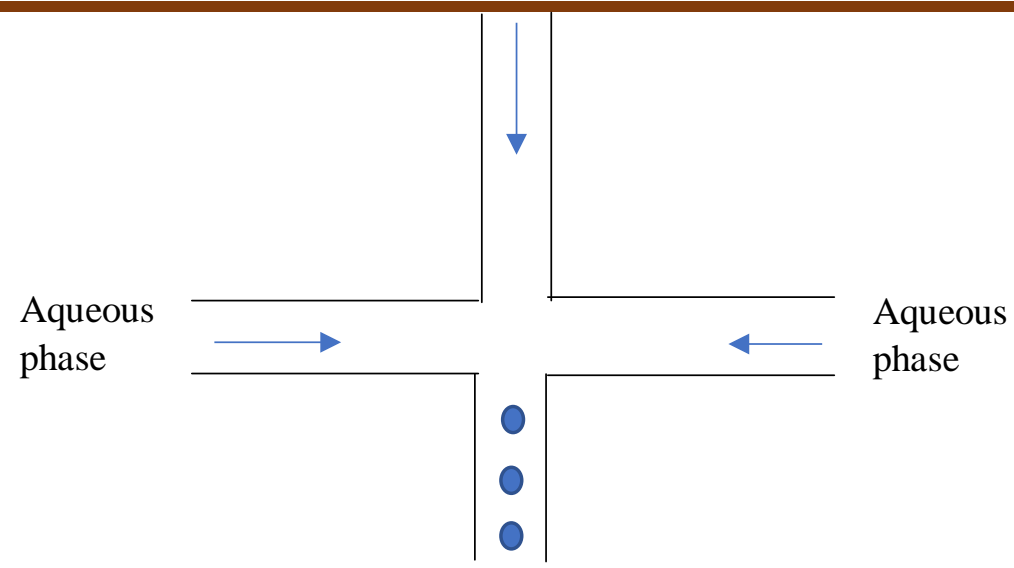

Figure 2: Microfluidics technique used to formulate insulin-loaded nanoparticles

\subsection{Nanoparticles characterization}

\subsubsection{Particle size}

The suspension of nanoparticles was diluted with distilled water to a suitable concentration and a vortex was used to dissolve the samples completely before the measurements. Dynamic light scattering (DLS) (Figure 3) was used to determine the average particle size and distribution of the nanoparticles which uses photon correlation spectroscopy (PCS) technique where the size of particles is related to the measurement of Brownian motion. The equipment used for measurement was Malvern Nano ZS (Malvern Instruments, UK) which analyzed the mean particle diameter (Z-average) and polydispersity index (PDI) of the nanoparticles at $25^{\circ} \mathrm{C}$ with $173^{\circ}$ detection optics and a 633 -nm laser. The particle size of nanoparticles was analyzed in triplicate for each formulation. Disposable sizing cuvettes were used for all the measurements. Malvern Zetasizer software (Version 7.11) was used to analyze the data generated by the instrument.

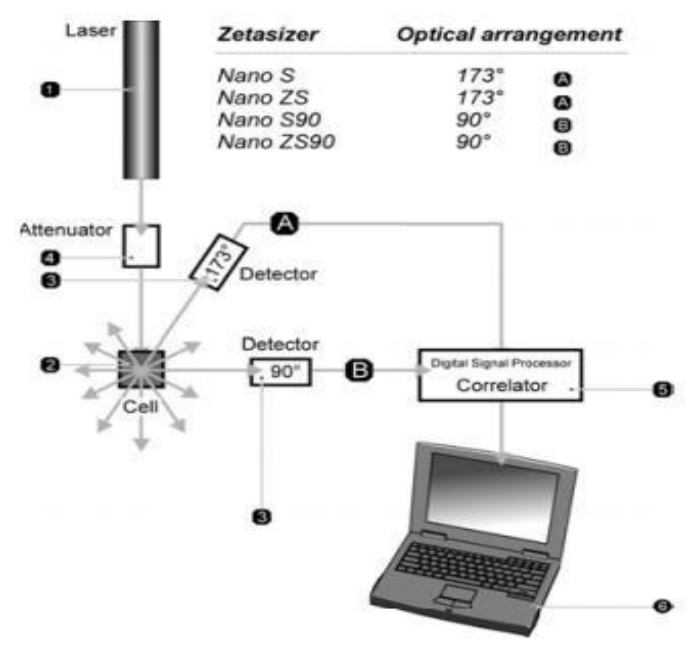

1. Laser - the light source

2. Cell - hold the sample

3. Detector - measure the scattered light

4. Attenuator - decrease the scattering intensity

5. Correlator - compares the intensity of scattering

6. Computer (Software) - analyze the data

Figure 3: Optical configurations of a dynamic light scattering device 


\subsubsection{Zeta potential}

The suspension of nanoparticles was used to analyze the zeta potential of the nanoparticles. The samples were diluted with $0.001 \mathrm{M}$ potassium chloride $(\mathrm{KCl})$ to a suitable concentration and a vortex was used to dissolve the samples completely prior to the measurements. By using Malvern Nano ZS (Malvern Instruments, UK), the zeta potential of the nanoparticles was analyzed by the laser Doppler electrophoresis technique where the Doppler effect is utilized in an electric field to measure the movement of charged particles. The samples were measured six times and disposable folded capillary cells were used for all the measurements.

The data generated were obtained from the instrument by using Malvern Zetasizer software (Version 7.11) for the analysis purpose.

\subsubsection{Surface analysis}

Surface morphology of nanoparticles was analyzed by using Hitachi S3000N scanning electron microscopy (SEM). To prepare the sample for viewing under the microscope, a small amount of lyophilized nanoparticles samples was sprinkled on metallic studs with double-sided conductive tape and the excess powder was removed by gently tapping the studs. The samples were then coated with Au/Pd by a sputter coater (Quorum SC7620). The lyophilized nanoparticles samples used for surface analyses were G3, G6, G9, G3M, G6M and G9M. The images of the samples were viewed at the magnification fields of $8,000,3,000$ and 2,000 .

\subsubsection{Insulin loading and entrapment efficiency}

The content of insulin was analyzed by direct extraction from intact nanoparticles. Insulin loaded nanoparticles (approximately 5mg) were weighed in the Eppendorf tubes for each formulation as shown in Table 3. The nanoparticles weighed were dissolved in $0.5 \mathrm{~mL}$ of $1 \mathrm{M}$ sodium hydroxide and incubated overnight at $37^{\circ} \mathrm{C}$ in an incubator (Raven Incubator, LTE Scientific). The nanoparticles were then neutralized with $0.5 \mathrm{~mL}$ of $1 \mathrm{M} \mathrm{HCl}$ and centrifuged for 5 minutes at 10,000 rpm. The supernatant was used for the quantification of total protein by using bicinchoninic acid (BCA) detection of copper reduction which is known as Pierce ${ }^{\mathrm{TM}}$ BCA protein assay kit. By using the reagent provided in the kit, this method reduced $\mathrm{Cu}^{2+}$ to $\mathrm{Cu}^{1+}$ by protein and combines with the selective colorimetric determination of the cuprous cation, $\mathrm{Cu}^{1+}$. The protein assay kit was used with protein standards of insulin prepared to obtain a calibration curve.

96-well microplates (Thermo Scientific ${ }^{\mathrm{TM}}$ ) were used to measure the absorbance of the samples of nanoparticles. The samples of nanoparticles and standards were measured in triplicate by xMark ${ }^{\mathrm{TM}}$ Microplate Absorbance Spectrophotometer (Bio-Rad Laboratories, Inc) at $562 \mathrm{~nm}$.

The data from the microplate was analyzed by using Microplate Manager ${ }^{\circledR} 6$ Software. The result of this assay was used to determine the percentage loading and hence, the entrapment efficiency was obtained. 
Table 3: Amount (mg) of insulin-loaded nanoparticles used to determine insulin loading and entrapment efficiency for double emulsion/solvent evaporation and microfluidics/salting out techniques

\begin{tabular}{|c|c|c|c|c|}
\hline \multirow[t]{2}{*}{ Type of nanoparticles } & \multicolumn{2}{|c|}{$\begin{array}{c}\text { Double Emulsion/Solvent } \\
\text { Evaporation }\end{array}$} & \multicolumn{2}{|c|}{ Microfluidics/Salting Out } \\
\hline & Formulation ID & Amount (mg) & Formulation ID & Amount (mg) \\
\hline \multirow[t]{3}{*}{ PLGA } & G1 & 5.3 & G1M & 5.1 \\
\hline & $\mathrm{G} 2$ & 5.0 & G2M & 5.0 \\
\hline & G3 & 5.2 & G3M & 5.1 \\
\hline \multirow[t]{3}{*}{ PLGA + 5\% PVP } & G4 & 5.3 & G4M & 5.0 \\
\hline & G5 & 5.1 & G5M & 5.0 \\
\hline & G6 & 5.2 & G6M & 5.0 \\
\hline \multirow{3}{*}{$\begin{array}{c}\mathrm{PLGA}+5 \% \mathrm{PVP}+5 \% \\
\text { PVP co-polymer }\end{array}$} & G7 & 5.1 & G7M & 5.1 \\
\hline & G8 & 5.0 & G8M & 5.2 \\
\hline & G9 & 5.0 & G9M & 5.2 \\
\hline
\end{tabular}

\subsubsection{Insulin in vitro release study}

Insulin loaded nanoparticles (approximately 5mg) were weighed in the Eppendorf tubes for each formulation as shown in Table 4. $1.0 \mathrm{~mL}$ of PBS solution was added into the Eppendorf tubes and incubated at body temperature which is $37^{\circ} \mathrm{C}$ in an incubator. Samples were withdrawn for analysis at time intervals of 2, 24, 48, 72, 96, 168 and 216 hours. The medium with nanoparticles was replaced with fresh PBS solution and maintained at $37^{\circ} \mathrm{C}$ after each withdrawal of samples. The samples were withdrawn to measure the rate of release of insulin at particular hour by using Pierce ${ }^{\mathrm{TM}}$ BCA protein assay kit. The protein assay kit was used with protein

standards of insulin prepared in order to get a calibration curve. 96-well microplates were used to measure the absorbance of the samples of nanoparticles. The samples of nanoparticles and standards were measured in triplicate by xMark $^{\mathrm{TM}}$ Microplate Absorbance Spectrophotometer at

562nm.Microplate Manager® 6 Software was used with the spectrophotometer for data analysis.

Table 4: Amount (mg) of insulin-loaded nanoparticles used to determine insulin loading and entrapment efficiency for double emulsion/solvent evaporation and microfluidics/salting out

\begin{tabular}{|c|c|c|c|c|}
\hline \multirow[t]{2}{*}{$\begin{array}{c}\text { Type of } \\
\text { nanoparticles }\end{array}$} & \multicolumn{2}{|c|}{$\begin{array}{l}\text { Double Emulsion/Solvent } \\
\text { Evaporation }\end{array}$} & \multicolumn{2}{|c|}{ Microfluidics/Salting Out } \\
\hline & Formulation ID & Amount (mg) & Formulation ID & Amount (mg) \\
\hline \multirow[t]{3}{*}{ PLGA } & G1 & 5.2 & G1M & 5.3 \\
\hline & $\mathrm{G} 2$ & 5.3 & G2M & 5.3 \\
\hline & G3 & 5.3 & G3M & 5.0 \\
\hline \multirow[t]{2}{*}{ PLGA + 5\% PVP } & G4 & 5.3 & G4M & 5.1 \\
\hline & G5 & 5.1 & G5M & 5.2 \\
\hline
\end{tabular}




\begin{tabular}{|c|c|c|c|c|}
\hline \hline & G6 & 5.3 & G6M & 5.2 \\
\hline PLGA + 5\% PVP + & G7 & 5.0 & G7M & 5.2 \\
\cline { 2 - 5 } & G8 PVP co-polymer & 5.1 & G8M & 5.1 \\
\cline { 2 - 5 } & G9 & 5.3 & G9M & 5.2 \\
\hline
\end{tabular}

\subsubsection{Compatibility and stability}

\subsubsection{Fourier-transform infrared (FTIR) analysis}

IR-spectra of each nanoparticles formulation were measured by using a FTIR spectrophotometer (IRAffinity-1S, Shimadzu Corporation). For FTIR analysis, lyophilized nanoparticles samples were used and the samples chosen for the analysis include G1, G6, G9, G3M, G6M and G9M. The raw materials such as the polymers used, PVA and insulin were analyzed as well for comparison with the nanoparticles formulated. The software used to analyze the results obtained is IRsolution.

\subsubsection{Differential Scanning Calorimetry (DSC)}

Thermal analysis was performed by using differential scanning calorimetry (DSC). An automated thermal analyzer known as DSC® Q1000 (TA Instruments) was used for the analysis. Lyophilized nanoparticles samples were used to analyze which include G3, G5, G7, G1M, G6M and G9M. Raw materials such as insulin, PLGA, PVA, PVP and PVP-copolymer were also analyzed for comparison with the nanoparticles formulated. Hermetic pans and lids (TA Instruments) were weighed by using a microbalance (Mettler-Toledo $\mathrm{GmbH}$, Laboratory \& Weighing Technologies) and approximately 4mg of sample was placed in each pan for all the formulations analyzed. The hermetic pan and lid with the sample was sealed and positioned in the sample holder of the DSC according to the numbered location. Indium was used to calibrate the temperature before and after sample runs were completed. An empty sealed hermetic pan and lid was used as the reference for all the sample runs. The software used with the instrument for data analysis is known as Universal Analysis 2000.

\section{Results and discussion}

\subsection{Particle size}

The particle size for three different formulations of nanoparticles by varying the technique used is presented in Table 5. Also, polydispersity index (PDI) of different formulations according to the techniques used, is also shown in the table. Based on the results, nanoparticles for the techniques used showed different sizes. When compared among three different formulations of nanoparticles for double emulsion/solvent evaporation technique, the results showed PLGA nanoparticles with the largest diameter of $364.3 \mathrm{~nm}$ as presented in the graph and followed by PLGA + 5\% PVP nanoparticles with the size of $343.3 \mathrm{~nm}$. PLGA $+5 \%$ PVP + PVP co-polymer nanoparticles were characterized with the smallest size of $302.2 \mathrm{~nm}$ for double emulsion/solvent evaporation technique. Polydispersity index (PDI) for three different formulations of nanoparticles was low, ranging from 0.179 to 0.388 . For instance, PLGA + 5\% PVP + PVP copolymer nanoparticles exhibited the lowest PDI of 0.179 and PLGA nanoparticles showed the highest PDI of 0.388 whereas PDI of PLGA $+5 \%$ PVP nanoparticles was 0.335 .

Based on the results presented in Table 6 for the microfluidics/salting out technique, PLGA nanoparticles were characterized with the largest diameter of $383.2 \mathrm{~nm}$ when compared to other types of nanoparticles. This was then followed by PLGA $+5 \%$ PVP + PVP co-polymer nanoparticles with the size diameter of $311.7 \mathrm{~nm}$. PLGA + 5\% PVP nanoparticles were the smallest with the size of $272.1 \mathrm{~nm}$ for the microfluidics/salting out technique. PDI of all the 
formulations of nanoparticles for microfluidic/salting out technique was low, ranging from 0.288 to 0.324 . PLGA $+5 \%$ PVP nanoparticles showed the highest PDI value of 0.324 and followed by PLGA nanoparticles with the second highest PDI of 0.305. However, PLGA + $5 \%$ PVP + PVP co-polymer showed the lowest PDI of 0.288 for microfluidics/salting out technique.

Overall, when the comparison between both of the techniques were made, the results were slightly different. Based on the results shown in Figure 4, it is shown that PLGA nanoparticles for both of the techniques was the largest but the smallest type of nanoparticles for double emulsion/solvent evaporation and microfluidics/salting out was PLGA + 5\% PVP + PVP copolymer nanoparticles and PLGA + 5\% PVP nanoparticles respectively. Moreover, PDI of the nanoparticles obtained for double emulsion/solvent evaporation technique was slightly different than that of microfluidics/salting out technique. PDI of PLGA + 5\% PVP + PVP co-polymer was shown to be the lowest for both techniques whereas the highest PDI for double emulsion/solvent evaporation and microfluidics/salting out was PLGA nanoparticles and PLGA + 5\% PVP nanoparticles respectively. Nanoparticles of double emulsion/solvent evaporation technique had broad range of PDI than the nanoparticles of microfluidics/salting out with narrow range of PDI.

Table 5: Size and PDI for each type of nanoparticles formulated by double emulsion/solvent evaporation technique

\begin{tabular}{|c|c|c|c|c|c|c|c|}
\hline Type of & Formulation & \multicolumn{3}{|c|}{ Size measurement $(\mathrm{nm})$} & Average of & Mean size per & $\mathrm{PDI} \pm \mathrm{SD}$ \\
\hline \multirow{3}{*}{ PLGA } & G1 & 296.5 & 289.6 & 315.6 & 300.6 & \multirow{3}{*}{$364.3 \pm 117.30$} & \multirow{3}{*}{$\begin{array}{l}0.388 \pm \\
0.180\end{array}$} \\
\hline & G2 & 477.0 & 522.8 & 499.1 & 499.6 & & \\
\hline & G3 & 282.9 & 287.7 & 307.6 & 292.7 & & \\
\hline \multirow{3}{*}{$\begin{array}{c}\text { PLGA }+5 \% \\
\text { PVP }\end{array}$} & G4 & 273.2 & 306.9 & 321.1 & 300.4 & \multirow{3}{*}{$343.4 \pm 50.0$} & \multirow{3}{*}{$\begin{array}{l}0.335 \pm \\
0.055\end{array}$} \\
\hline & G5 & 315.2 & 323.8 & 355.7 & 331.6 & & \\
\hline & G6 & 371.7 & 395.7 & 427.2 & 398.2 & & \\
\hline \multirow{3}{*}{$\begin{array}{c}\text { PLGA + 5\% } \\
\text { PVP + 5\% } \\
\text { PVP } \\
\text { copolymer }\end{array}$} & G7 & 304.8 & 312.3 & 336.1 & 317.7 & $302.2 \pm 15.80$ & \multirow{3}{*}{$\begin{array}{l}0.179 \pm \\
0.012\end{array}$} \\
\hline & G8 & 326.1 & 296.1 & 286.5 & 302.9 & & \\
\hline & G9 & 286.0 & 282.5 & 289.8 & 286.1 & & \\
\hline
\end{tabular}


DOI : https://dx.doi.org/10.26808/rs.aj.i8v1.02

American Journal of Sustainable Cities and Society

Issue 8, Vol. 1 January- December 2019

Available online on http://www.rspublication.com/ajscs/ajsas.html

ISSN $2319-7277$

Table 6: Size and PDI with standard deviation for each type of nanoparticles formulated by microfluidics/salting out technique

\begin{tabular}{|c|c|c|c|c|c|c|c|}
\hline \multirow{2}{*}{$\begin{array}{c}\text { Type of } \\
\text { nanoparticles }\end{array}$} & \multirow{2}{*}{$\begin{array}{c}\begin{array}{c}\text { Formulation } \\
\text { ID }\end{array} \\
\text { G1M }\end{array}$} & \multicolumn{3}{|c|}{ Size measurement (nm) } & \multirow{2}{*}{$\begin{array}{c}\begin{array}{c}\text { Average size } \\
\text { (nm) }\end{array} \\
456.1\end{array}$} & \multirow{2}{*}{$\begin{array}{c}\text { Mean size per } \\
\text { formulation }(\mathrm{nm}) \\
\pm S \mathrm{SD}\end{array}$} & \multirow[t]{2}{*}{ PDI \pm SD } \\
\hline & & 448.3 & 474.8 & 445.3 & & & \\
\hline \multirow[t]{2}{*}{ PLGA } & G2M & 367.7 & 424.5 & 361.4 & 384.5 & \multirow[t]{2}{*}{$383.2 \pm 73.6$} & \multirow[t]{2}{*}{$0.305 \pm 0.076$} \\
\hline & G3M & 290.3 & 308.0 & 328.8 & 309.0 & & \\
\hline \multirow{3}{*}{$\begin{array}{c}\text { PLGA + 5\% } \\
\text { PVP }\end{array}$} & G4M & 255.2 & 308.3 & 262.1 & 275.2 & \multirow{3}{*}{$272.1 \pm 12.2$} & \multirow{3}{*}{$0.324 \pm 0.045$} \\
\hline & G5M & 233.8 & 270.4 & 271.8 & 258.7 & & \\
\hline & G6M & 277.6 & 289.2 & 280.9 & 282.6 & & \\
\hline \multirow{3}{*}{$\begin{array}{c}\text { PLGA + 5\% } \\
\text { PVP + 5\% } \\
\text { PVP } \\
\text { copolymer }\end{array}$} & G7M & 238.2 & 250.6 & 291.2 & 260.0 & \multirow{3}{*}{$310.7 \pm 52.9$} & \multirow{3}{*}{$0.288 \pm 0.048$} \\
\hline & G8M & 309.9 & 301.6 & 307.5 & 306.3 & & \\
\hline & G9M & 343.9 & 410.1 & 342.9 & 365.6 & & \\
\hline
\end{tabular}

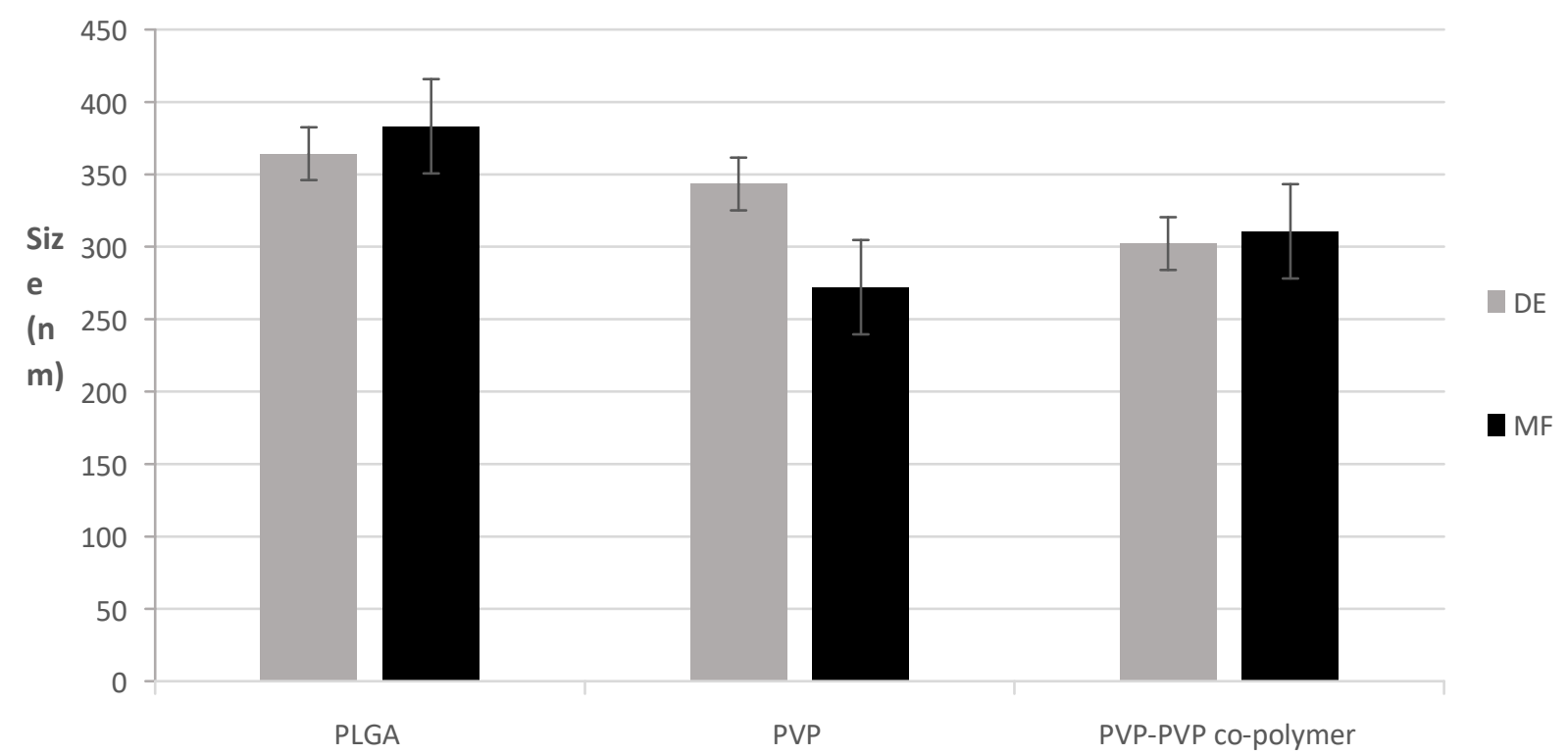

Type of nanoparticles

Figure 4: Size of various nanoparticles formulated by using double emulsion/solvent evaporation and microfluidics/salting out techniques 
In the formulation of nanoparticles, size is one of the essential criteria involved in the characterization of nanoparticles. Size, as well as size distribution of the nanoparticle systems affect several other characteristics of nanoparticles which include toxicity, ability to target, biological fate and in vivo distribution. Furthermore, size also plays an important role in other properties of nanoparticles such as stability, drug loading and drug release (Kumar et al., 2017). Thus, in general, an ideal size of a nanoparticle which usually prepared from polymers is about $200 \mathrm{~nm}$ to $500 \mathrm{~nm}$ as studies has revealed that in drug delivery systems, sub-micron sized nanoparticles are more beneficial over microparticles (Mora-Huertas, Fessi and Elaissari, 2010; Panyam and Labhasetwar, 2012). For oral drug delivery system, nanoparticles must meet several criteria, one of which, the size of the nanoparticles must be small $(\leq 500 \mathrm{~nm})$ with a uniform size distribution because it is beneficial to the cellular uptake of the nanoparticles (He et al., 2010; Mimi et al., 2015).

In the present study, size of the nanoparticles formulated by using different techniques is characterized by using dynamic light scattering (DLS) method. The sizes of the nanoparticles for both techniques were between $272.1 \mathrm{~nm}$ and $383.2 \mathrm{~nm}$. From the results, it was observed that PLGA nanoparticles were the largest for both of the techniques but two other formulations of nanoparticles were smaller in size when compared to PLGA nanoparticles. This indicates that the addition of other type of polymers can decrease the size of the nanoparticles depending on the type, molecular weight and the amount of the polymer. However, the fact that particle size is affected by the type of polymers used in this study is not quite clear as the characterization was only done once for each formulation and hence, no comparison of results can be made. Thus, repetition of the formulations of nanoparticles is needed with various composition or concentration of the polymers used to compare and investigate how the concentration and type of polymer can affect the particle size. For instance, some studies have shown that particle size increases with increasing molecular weight of the polymer (Zhu et al., 2001; Cui et al., 2006). On the other hand, a study has revealed that by increasing molecular weight of PVP, the size of the nanoparticles can be decreased (Izu et al., 2011). Therefore, in the present study, the molecular weight of the polymers involved may have affected the size of the nanoparticles but more evidences are needed to investigate the relationship between molecular weight of the polymers used and size of nanoparticles.

In addition, it is observed that the standard deviation for PLGA nanoparticles for double emulsion technique is relatively high. This is because nanoparticles with formulation ID of G2 (PLGA nanoparticles) showed large sized nanoparticles when compared to G1 and G3 which may be contributed to the agglomeration of particles in the solution that increased the particle size (ElNaggar et al., 2015). Also, the nanoparticles with formulation ID of G1M, G2M and G9M showed slightly bigger nanoparticles when compared to nanoparticles of other formulation IDs which may be affected by the agglomeration of nanoparticles in the solution. However, when compared among both of the techniques based on the results obtained, nanoparticles of microfluidics/salting out technique exhibited low variation in the size except for PLGA $+5 \%$ PVP $+5 \%$ PVP copolymer nanoparticles which affected by nanoparticles with formulation ID of G9M. Nanoparticles of microfluidics/salting out technique also showed narrower PDI which indicates that the nanoparticles formulated by using microfluidics/salting out technique are more consistent

than those of double emulsion/solvent evaporation technique. This is because microfluidics/salting out technique formulates uniform nanoparticles where the size of the nanoparticles formed can be controlled which results in narrower size distribution(Perez et al., 
2015). Also, the size of the nanoparticles of microfluidics/salting out technique can be kept constant by altering the flow rate. On the contrary, double emulsion/solvent evaporation technique formulates large droplets as the nanoparticles are formulated by mixing randomly during homogenization (Vladisavljević et al., 2014).

Overall, size of nanoparticles is affected by some of the factors involved in the techniques used. For instance, factors that influence the size of nanoparticles by using double emulsion/solvent evaporation technique are the polymers used, nature and volume of the organic phase, nature and volume of aqueous phase and nature and concentration of surfactants. Besides, the diameter of the nanoparticles can be controlled by altering the intensity and duration of shear rate or homogenization during the emulsification process (Moinard-Chécot et al., 2008). However, it is beneficial to formulate nanoparticles by using microfluidics/salting out technique as uniform size distribution of droplets can be achieved by controlling the flow rate during the process.

In the pharmaceutical industry, stability is one of the important aspect which decides if the nanoparticles can be utilized in the field. Therefore, the size of the nanoparticles should be measured against storage time at different temperatures to prevent problems such as Ostwald ripening, coagulation or aggregation (Moinard-Chécot et al., 2008). Also, the size of the nanoparticles should be measured by using freeze dried samples in order to compare the results.

\subsection{Zeta potential}

Based on the results shown in Table 7, PLGA nanoparticles exhibited negative zeta potential value of $-7.07 \mathrm{mV}$ for double emulsion/solvent evaporation technique but the value was much higher for microfluidics/salting out technique with negative zeta potential of $-21.18 \mathrm{mV}$. PLGA $+5 \%$ PVP nanoparticles of double emulsion/solvent evaporation technique were characterized with highest negative zeta potential of $-7.24 \mathrm{mV}$ whereas the value of zeta potential for nanoparticles of microfluidics/salting out technique was $-25.99 \mathrm{mV}$. However, PLGA $+5 \%$ PVP + 5\% PVP co-polymer nanoparticles exhibited the lowest negative zeta potential with the value of $-6.76 \mathrm{mV}$ for double emulsion/solvent evaporation technique but the nanoparticles exhibited the highest negative zeta potential of $-27.42 \mathrm{mV}$ for the microfluidics/salting out technique. PLGA $+5 \%$ PVP nanoparticles were characterized with the negative zeta potential value of $-7.24 \mathrm{mV}$ and $-25.99 \mathrm{mV}$ for double emulsion/solvent evaporation and microfluidics/salting out technique respectively.

When negative zeta potential of the nanoparticles for three different formulations were compared among the techniques used (Figure 5), it was observed that microfluidics technique exhibited higher negative zeta potential values than the nanoparticles of the double emulsion technique. For instance, for double emulsion/solvent evaporation technique, PLGA $+5 \%$ PVP nanoparticles exhibited the highest negative zeta potential value and PLGA + 5\% PVP + $5 \%$ PVP co-polymer nanoparticles exhibited the lowest negative zeta potential value. However, for microfluidics/salting out technique, PLGA + 5\% PVP + 5\% PVP co-polymer showed the highest negative zeta potential value and PLGA nanoparticles showed the lowest value. 
DOI : https://dx.doi.org/10.26808/rs.aj.i8v1.02

American Journal of Sustainable Cities and Society

Issue 8, Vol. 1 January- December 2019

Available online on http://www.rspublication.com/ajscs/ajsas.html

ISSN $2319-7277$

Table 7: Zeta potential for nanoparticles formulated by double emulsion/solvent evaporation technique

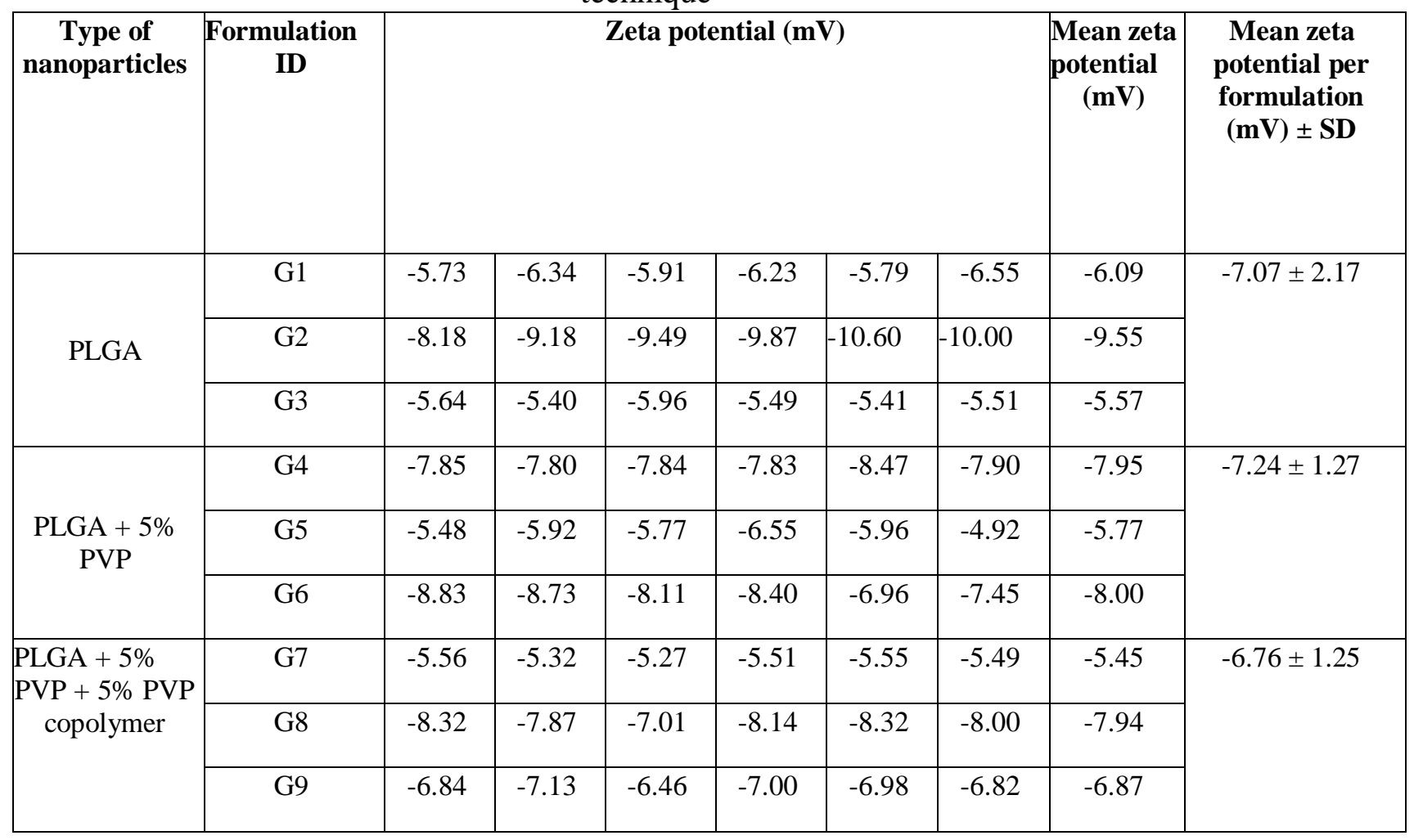

Table 8: Zeta potential for nanoparticles formulated by microfluidics/salting out technique

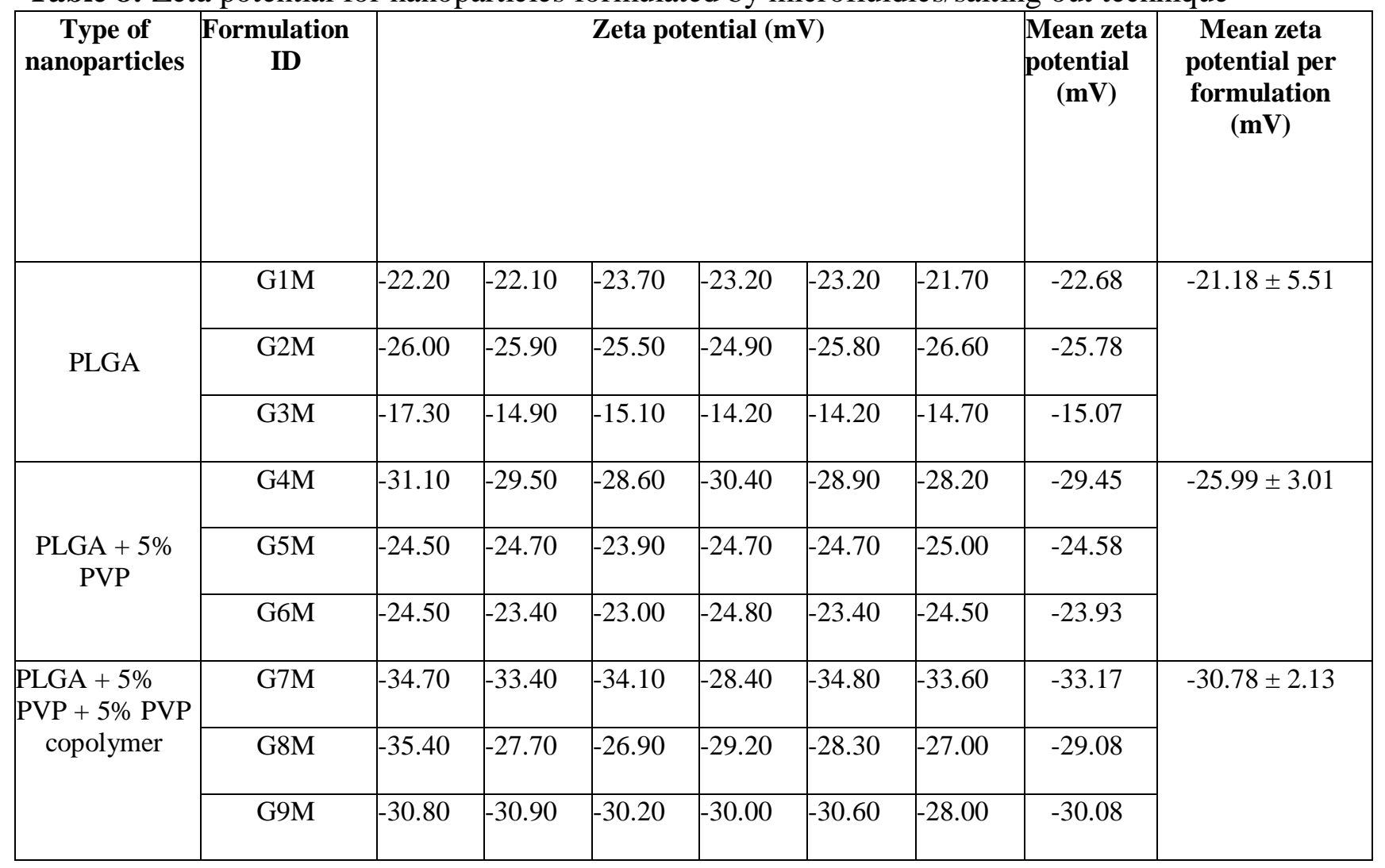




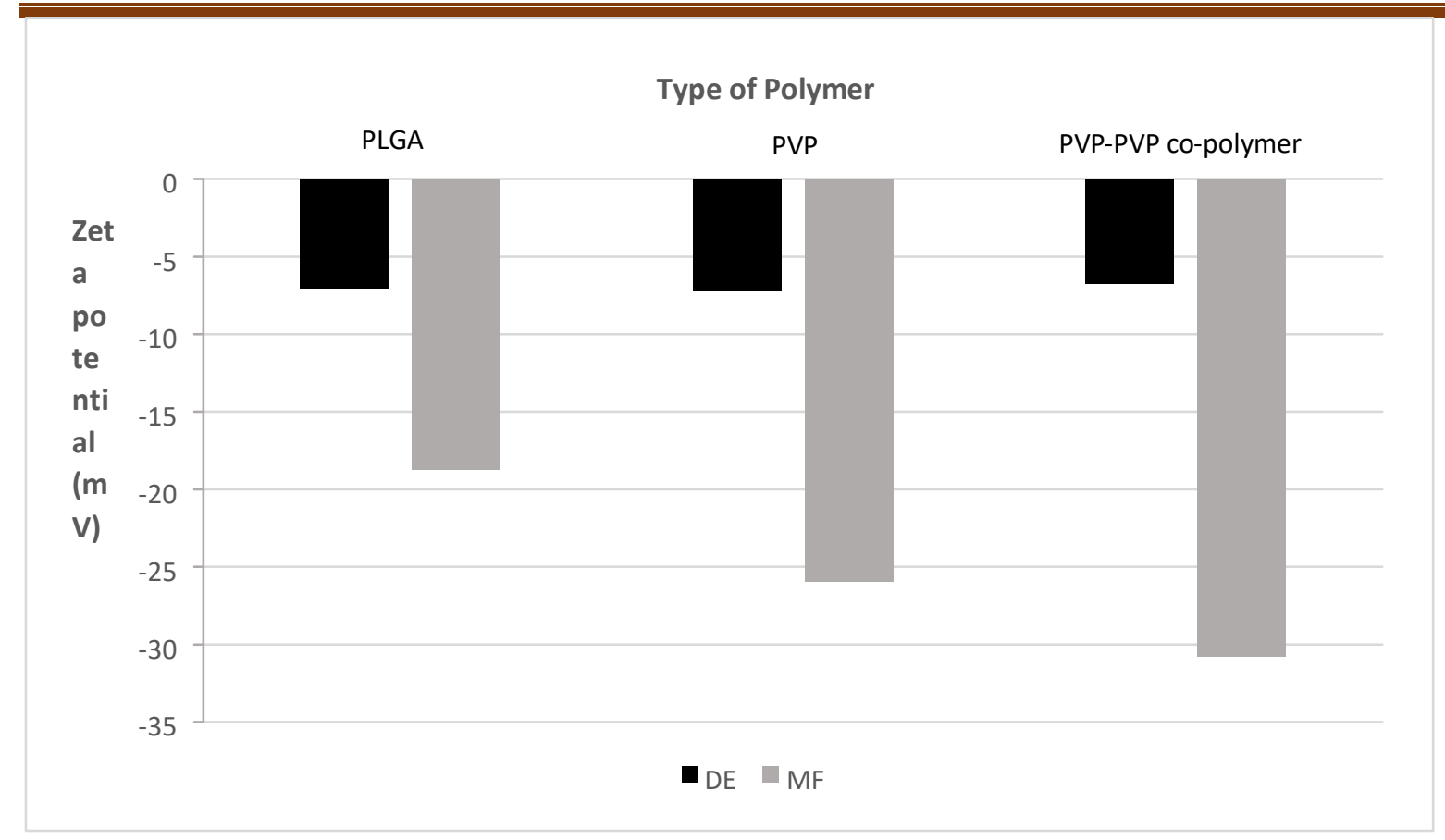

Figure 5: Zeta potential of various nanoparticles formulated by using double emulsion/solvent evaporation and microfluidics/salting out techniques

To achieve an optimal effect of pharmacokinetic, the control of surface chemistry or characteristics on the release of insulin loaded nanoparticles is important. Thus, zeta potential is an essential parameter in order to investigate the electric potential of nanoparticles which is used to determine the surface charge property of nanoparticles. Zeta potential of a nanoparticle generally depends on the $\mathrm{pH}$ of the medium, chemical nature of the stabilizing agent and chemical nature of the polymer used (Mora-Huertas, Fessi and Elaissari, 2010). In addition, zeta potential is also an important parameter in order to maintain stability in aqueous nanodispersions and to confirm if a charged active drug or material is entrapped on the surface or in the center of the nanoparticle (Honary et al., 2010).

Based on the results tabulated, it can be concluded that the nanoparticles formulated by double emulsion/solvent evaporation and microfluidics/salting out technique were negatively charged. All the nanoparticles formulated by using both of the techniques exhibited negative zeta potential because of the presence of carboxylic groups in the polymers used to prepare the nanoparticles (Mora-Huertas, Fessi and Elaissari, 2010). For instance, in PLGA nanoparticles, the presence of free carboxyl end groups in the polymer chains of PLGA makes the nanoparticles to be more hydrophilic which means the insulin, which is hydrophilic in nature, incorporated into PLGA polymer is entrapped in the hydrophobic core of the polymer. PVP is an amphiphilic polymer with the presence of a pyrrolidone group which is hydrophilic in nature and an alkyl side group which is hydrophobic in nature (Li et al., 2017). Therefore, PLGA + 5\% PVP nanoparticles showed negative zeta potential due to the presence of carboxyl end groups in the PLGA and pyrrolidone group in PVP polymer. Also, due to the presence of carboxyl groups in PLGA and pyrrolidone groups in PVP and PVP co-polymer, PLGA + 5\% PVP $+5 \%$ PVP copolymer nanoparticles exhibited negative zeta potential. It was observed that the PLGA + $5 \%$ PVP $+5 \%$ PVP co-polymer nanoparticles showed lower negative zeta potential than other nanoparticles for double emulsion/solvent evaporation technique probably due to its long chain of vinylpyrrolidone co-polymer. 
When the two techniques involved in the formulation of the nanoparticles were compared, higher negative zeta potential values were specifically showed by nanoparticles of microfluidics/salting out technique which indicates the presence of electrostatic repulsion that avoid agglomeration of the nanoparticles due to the strong repellent forces among them (Sawant and Dodiya, 2008; Yu et al., 2015). Furthermore, higher negative zeta potential of nanoparticles for microfluidics/salting out technique shown may be due to the effect from the medium in which it was dissolved (Kumar et al., 2017). For instance, salting out method was used in the microfluidics technique which indicates that the salt used in the technique may have caused the nanoparticles to exhibit stronger zeta potential than nanoparticles of double emulsion technique. In addition, a study has shown that the nanoparticles prepared by using salting out technique always have high negative values as the zeta potential of the nanoparticles is affected by the preparation technique. This may be caused by the polar groups of the polymers used in the microfluidics/salting out technique which are located on the particle surface whereby the hydrophobic moiety of polymers used predominates on the surface of nanoparticles of double emulsion/solvent evaporation technique (Mora-Huertas et al., 2012).

Once administered, nanoparticles can easily be recognized by the human defense system such as mononuclear phagocyte system which indicates that nanoparticles can be cleared easily by the defense system that lowers the effectiveness of the nanoparticles (Bakhru et al., 2013). Therefore, it is important to consider the surface properties which include the hydrophobicity and charge of the nanoparticles in the formulation to avoid opsonization in the blood which is caused by aggregation of nanoparticles to reduce surface energy. To avoid opsonization, nanoparticles can be coated with polymers such as polyethylene glycol (PEG) which is biocompatible and hydrophilic that can prolong the circulation time of nanoparticles (Yu et al., 2016). Thus, present study on the nanoparticles can be improved with the addition of PEG by carrying out in vivo studies as well to investigate the circulation time of nanoparticles.

\subsection{Surface analysis}
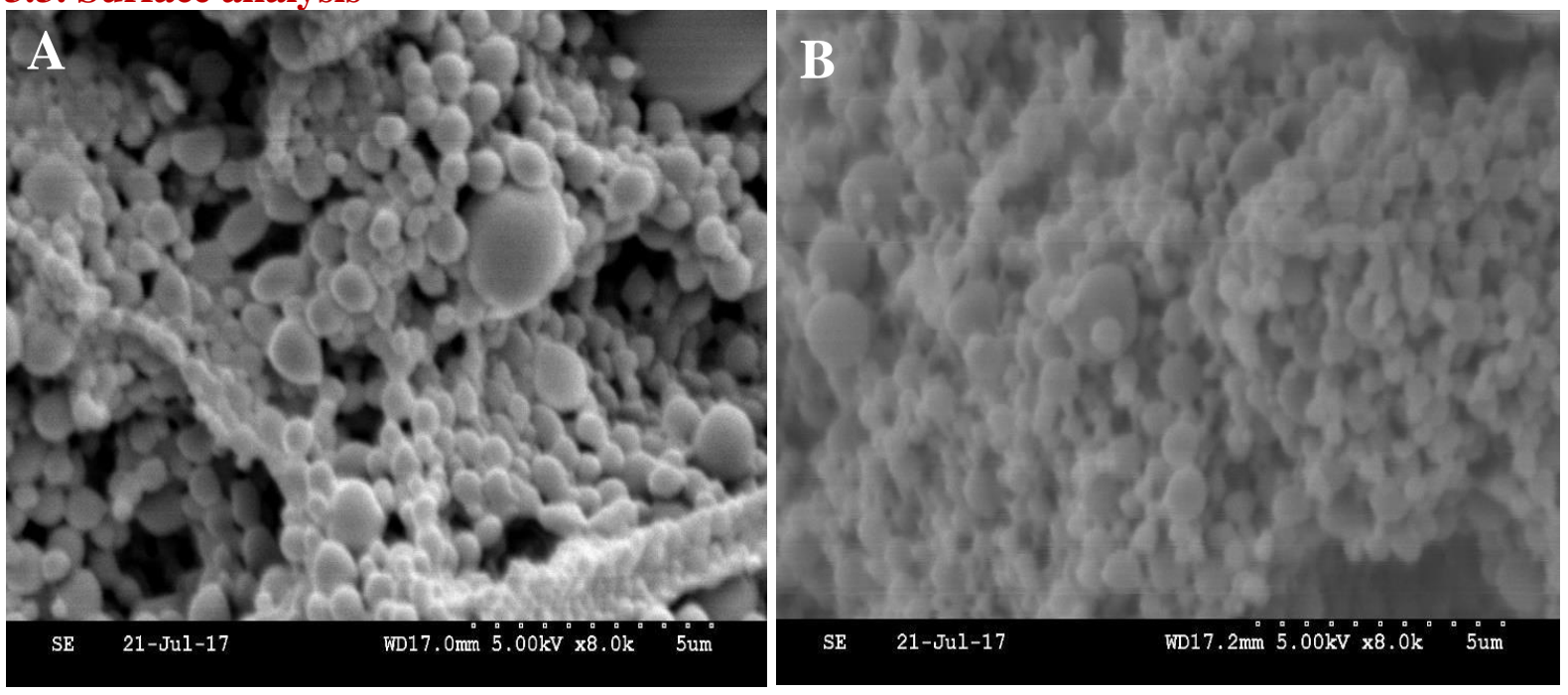

Figure 6: SEM images of PLGA nanoparticles formulated by: (A) double emulsion/solvent evaporation technique; (B) microfluidics/salting out technique 

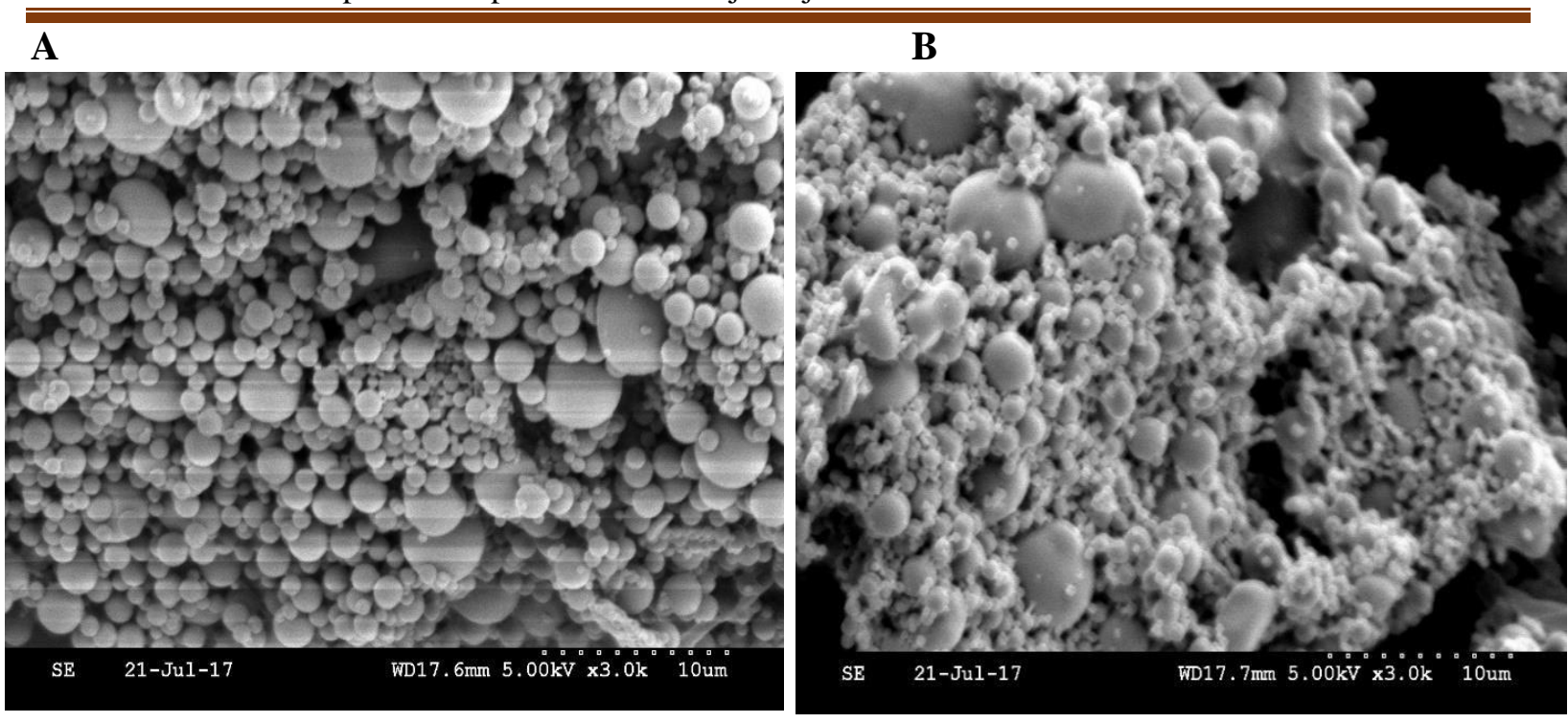

Figure 7: SEM images of PLGA + 5\% PVP nanoparticles formulated by: (A) double emulsion/solvent evaporation technique; (B) microfluidics/salting out technique
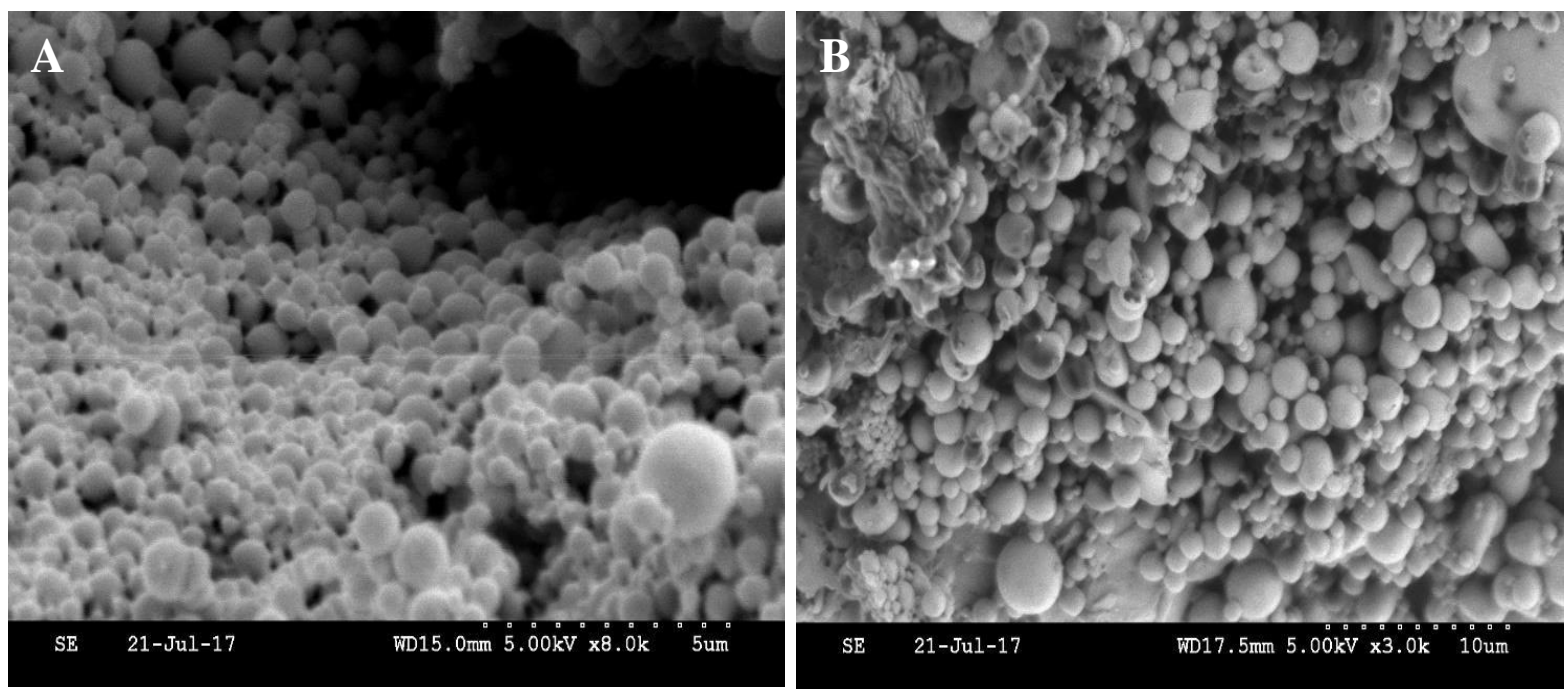

Figure 8: SEM images of PLGA + 5\% PVP + $5 \%$ PVP co-polymer nanoparticles formulated by:

(A) double emulsion/solvent evaporation technique; (B) microfluidics/salting out technique

Based on the SEM images observed, it is concluded that the nanoparticles of the three formulations were in spherical shape with relatively small size ranging from $270 \mathrm{~nm}$ to 400 $\mathrm{nm}$. From the observation made, the surface of the nanoparticles is free from pores. It was also observed that the nanoparticles formulations with different techniques prepared showed a slight difference in the size variation. For instance, nanoparticles prepared by double emulsion/solvent evaporation technique were larger in size when compared to nanoparticles of microfluidics/salting out technique.

However, nanoparticles prepared by microfluidics/salting out technique exhibited homogenous distribution with low size variation relative to those prepared by double emulsion/solvent evaporation technique. This is because microfluidics/salting out technique provides a precise control of the size with homogenous distribution and low variation in size which is clearly an advantage in the formulation of nanoparticles with proteins when compared to double emulsion technique. Also, the size of the nanoparticles can be controlled 
by changing flow rates in microfluidics technique to ensure consistency in the size of nanoparticles (Keohane et al., 2014). However, in the future study, surface morphology of nanoparticles after 9 days of in vitro release should be studied as well in order to compare the appearance of the nanoparticles after the release of insulin from the nanoparticles. Size distribution of nanoparticles should be determined as well.

\subsection{Insulin loading and entrapment efficiency}

Table 9: Entrapment efficiency (EE) calculated for each type of nanoparticles formulated by double emulsion/solvent evaporation technique

\begin{tabular}{|c|c|c|c|c|c|c|c|c|}
\hline \multirow{2}{*}{$\begin{array}{c}\begin{array}{c}\text { Type of } \\
\text { Nanoparticles }\end{array} \\
\text { PLGA }\end{array}$} & \multirow{2}{*}{$\begin{array}{c}\begin{array}{c}\text { Formulation } \\
\text { ID }\end{array} \\
\text { G1 }\end{array}$} & \multicolumn{3}{|c|}{ Absorbance at $562 \mathrm{~nm}$} & \multirow{2}{*}{$\begin{array}{c}\begin{array}{c}\text { Mean } \\
\text { absorbance }\end{array} \\
0.160\end{array}$} & \multirow{2}{*}{$\begin{array}{c}\begin{array}{c}\text { Concentration } \\
(\boldsymbol{\mu g} / \mathbf{m g})\end{array} \\
13.39\end{array}$} & \multirow{2}{*}{$\begin{array}{r}\text { EE (\%) } \\
66.96\end{array}$} & \multirow{2}{*}{$\begin{array}{c}\begin{array}{c}\text { Mean EE } \\
(\%)\end{array} \\
60.12 \pm 13.15\end{array}$} \\
\hline & & 0.161 & 0.159 & 0.160 & & & & \\
\hline & $\mathrm{G} 2$ & 0.161 & 0.161 & 0.169 & 0.164 & 13.69 & 68.43 & \\
\hline & G3 & 0.106 & 0.106 & 0.103 & 0.105 & 9.00 & 44.96 & \\
\hline \multirow{3}{*}{$\begin{array}{c}\text { PLGA + 5\% } \\
\text { PVP }\end{array}$} & G4 & 0.104 & 0.108 & 0.117 & 0.110 & 9.37 & 46.83 & \multirow[t]{3}{*}{$49.18 \pm 5.03$} \\
\hline & G5 & 0.130 & 0.131 & 0.129 & 0.130 & 11.00 & 54.96 & \\
\hline & G6 & 0.105 & 0.110 & 0.106 & 0.107 & 9.15 & 45.76 & \\
\hline \multirow{3}{*}{$\begin{array}{c}\text { PLGA + 5\% } \\
\text { PVP + 5\% PVP } \\
\text { co-polymer }\end{array}$} & G7 & 0.104 & 0.108 & 0.103 & 0.105 & 9.00 & 44.96 & \multirow[t]{3}{*}{$47.00 \pm 4.50$} \\
\hline & G8 & 0.101 & 0.101 & 0.105 & 0.102 & 8.78 & 43.89 & \\
\hline & G9 & 0.123 & 0.124 & 0.122 & 0.123 & 10.43 & 52.16 & \\
\hline
\end{tabular}

Table 10: Entrapment efficiency (EE) calculated for each type of nanoparticles formulated by double emulsion/solvent evaporation technique

\begin{tabular}{|c|c|c|c|c|c|c|c|c|}
\hline $\begin{array}{c}\text { Type of } \\
\text { Nanoparticles }\end{array}$ & $\begin{array}{c}\text { Formulation } \\
\text { ID }\end{array}$ & \multicolumn{3}{|c|}{ Absorbance at $562 \mathrm{~nm}$} & $\begin{array}{c}\text { Mean } \\
\text { absorbance }\end{array}$ & $\begin{array}{c}\text { Concentration } \\
(\mu \mathrm{g} / \mathrm{mg})\end{array}$ & EE $(\%)$ & $\begin{array}{c}\text { Mean EE } \\
(\%)\end{array}$ \\
\hline \multirow[t]{3}{*}{ PLGA } & G1M & 0.106 & 0.103 & 0.102 & 0.104 & 8.89 & 44.43 & \multirow[t]{3}{*}{$42.47 \pm 1.71$} \\
\hline & G2M & 0.094 & 0.099 & 0.098 & 0.097 & 8.35 & 41.76 & \\
\hline & G3M & 0.095 & 0.095 & 0.097 & 0.096 & 8.25 & 41.23 & \\
\hline \multirow{3}{*}{$\begin{array}{c}\text { PLGA + 5\% } \\
\text { PVP }\end{array}$} & G4M & 0.130 & 0.129 & 0.131 & 0.130 & 11.00 & 54.96 & \multirow[t]{3}{*}{$48.43 \pm 5.69$} \\
\hline & G5M & 0.104 & 0.107 & 0.110 & 0.107 & 9.15 & 45.76 & \\
\hline & G6M & 0.105 & 0.103 & 0.104 & 0.104 & 8.90 & 44.56 & \\
\hline \multirow{3}{*}{$\begin{array}{c}\text { PLGA + 5\% } \\
\text { PVP + 5\% } \\
\text { PVP } \\
\text { copolymer }\end{array}$} & G7M & 0.110 & 0.109 & 0.105 & 0.108 & 9.23 & 46.16 & \multirow[t]{3}{*}{$51.49 \pm 12.49$} \\
\hline & G8M & 0.099 & 0.100 & 0.098 & 0.099 & 8.51 & 42.56 & \\
\hline & G9M & 0.143 & 0.186 & 0.142 & 0.157 & 13.15 & 65.76 & \\
\hline
\end{tabular}




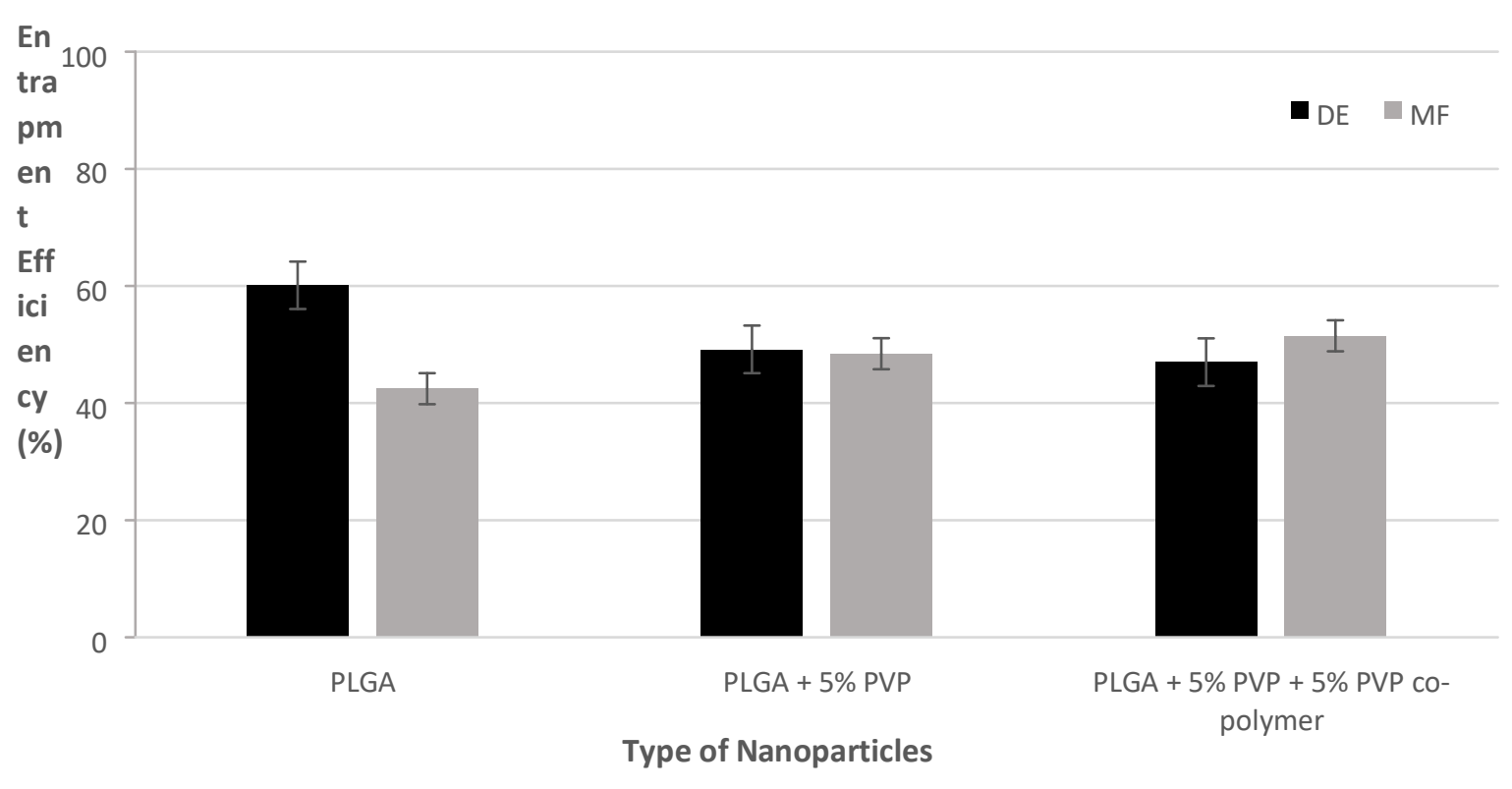

Figure 9: Entrapment efficiency of different types of nanoparticles formulated by double emulsion/solvent evaporation and microfluidics/salting out technique

The results of insulin loading and entrapment efficiency are tabulated in Tables 9 and 10 for double emulsion/solvent evaporation and microfluidics/salting out techniques respectively. The absorbance reading for each formulation was measured three times and the average was obtained. Concentration of each sample was calculated by using the equation obtained from the calibration curve. Encapsulation efficiency for each formulation was calculated as a percentage where the concentration of actual insulin loading (concentration obtained from the equation, $\mu \mathrm{g} / \mathrm{mg}$ ) divided by theoretical loading which was $20 \mu \mathrm{g} / \mathrm{mg}$ $(w / w)$. The average of encapsulation efficiency was obtained by calculating the mean of three samples for each formulation. Standard deviation for the mean of each formulation was obtained whereby the variation of samples from the mean can be identified.

Based on the results presented for nanoparticles of double emulsion/solvent evaporation technique, PLGA nanoparticles showed the highest entrapment efficiency of $60.12 \%$ and followed by PLGA + 5\% PVP nanoparticles with the entrapment efficiency of $49.18 \%$. PLGA $+5 \%$ PVP + 5\% PVP co-polymer nanoparticles exhibited the lowest average of entrapment efficiency with the value of $47.00 \%$. However, when the results are compared with the microfluidics/salting out technique, PLGA $+5 \%$ PVP $+5 \%$ PVP co-polymer nanoparticles showed the highest entrapment efficiency of $51.49 \%$ and followed by PLGA + $5 \%$ PVP nanoparticles with the value of $48.43 \%$. PLGA nanoparticles showed the lowest entrapment efficiency of $42.47 \%$. Overall, insulin entrapment efficiency of nanoparticles formulated by double emulsion/solvent evaporation technique increased with increasing number of polymers used whereas insulin entrapment efficiency of nanoparticles formulated by microfluidics/salting out technique decreased with decreasing number of polymers used.

In the pharmaceutical field, it is very challenging to encapsulate proteins in the nanoparticles as numerous organic solvents involved in the preparation of protein-loaded nanoparticles can denature or damage the biological activity of proteins involved (Yu et al., 2016). Hence, to confirm that the insulin is entrapped safely in the nanoparticles, the insulin loading and entrapment efficiency was performed. For drug administration, a nanoparticulate medium must consist of a high drug-loading capacity with reduced amount of matrix materials. Drug 
loading is mainly affected by the chemical nature of the drug which include solubility and ionization (ElNaggar et al., 2015). Generally, there are two ways to load a drug into the nanoparticle system which include incorporation method and adsorption/absorption technique. Incorporation method involves the integration of drug during the production of nanoparticles whereas

adsorption/absorption technique involves the absorption of drug by incubation of the carrier with the drug solution after the production of nanoparticles (Nagal\&Singla, 2013). In this study, drug was loaded into the nanoparticle system by the incorporation method.

Based on the results obtained for insulin loading and encapsulation efficiency, it can be concluded that insulin had successfully been entrapped in the nanoparticles. Insulin loading and entrapment efficiency for double emulsion/solvent evaporation technique were the highest in PLGA nanoparticles and then followed by PLGA + 5\% PVP nanoparticles and PLGA $+5 \%$ PVP $+5 \%$ PVP co-polymer which indicates that the encapsulation efficiency decreases with the addition of PVP polymer and PVP co-polymer in the composition of the nanoparticles. This is because PLGA nanoparticles had the largest diameter among all the nanoparticles which indicates that the presence of large cores in the PLGA nanoparticles allowed a great amount of insulin to be entrapped (Díaz and Vivas-Mejia, 2013). From this, it was observed that the size of nanoparticles affects the loading and entrapment efficiency of insulin-loaded nanoparticles. However, the result for nanoparticles of microfluidics/salting out was different than that of nanoparticles of double emulsion/solvent evaporation technique. PLGA $+5 \%$ PVP $+5 \%$ PVP co-polymer nanoparticles showed the highest encapsulation efficiency among the other nanoparticles. PLGA nanoparticles supposed to show the highest encapsulation efficiency based on the nanoparticle size as well. This probably caused by a phenomenon influenced by the surfactants and polymers used whereby the entry of hydrophilic groups of the polymers into the aqueous phase may have caused the drug from the nanoparticle to leak into the outer aqueous solution which results in low encapsulation efficiency (Mora-Huertas, Fessi and Elaissari, 2010).

When both of the techniques were compared, nanoparticles of double emulsion/solvent evaporation technique had higher entrapment efficiency especially for PLGA nanoparticles and PLGA $+5 \%$ PVP nanoparticles. In double emulsion/solvent evaporation, during the solidification stage of polymer, diffusion of hydrophilic drugs take place whereby polymers with low solubility in the organic solvent will solidify faster during emulsification and as a result, provide the higher encapsulation efficiency (Lu, Bei and Wang, 1999). On the other hand, based on the study carried out by Keohane et al. (2014), higher entrapment efficiency of drug was observed when microfluidics/salting out technique was used because there was a risk to lose a high amount of drug during conventional methods. In addition, for the protein encapsulation, homogenization process in double emulsion method is destructive to the biological activity of insulin due to high shear stress. Alternatively, sonication can be used instead of homogenization as the biological activity of insulin is preserved (Fonte et al., 2012).

Thus, repetition is needed for present study to determine the insulin loading and entrapment efficiency by using both direct and indirect methods in order to compare the results. Indirect method can be determined by using radioimmunoassay whereby nonencapsulated free insulin content can be determined in the supernatant (Haggag et al., 2016). Also, for the direct method, each sample can be assayed for six times rather than triplicate to ensure accuracy of the results. 
DOI : https://dx.doi.org/10.26808/rs.aj.i8v1.02

American Journal of Sustainable Cities and Society

Issue 8, Vol. 1 January- December 2019

Available online on http://www.rspublication.com/ajscs/ajsas.html

ISSN $2319-7277$

\subsection{Insulin in vitro release study}

Table 11: Rate of release at various time intervals for different types of nanoparticles formulated by double emulsion/solvent evaporation technique

\begin{tabular}{|c|c|c|c|c|c|c|c|}
\hline & \multicolumn{7}{|c|}{ Rate of release $(\%)$} \\
\hline \multirow[t]{2}{*}{ Type of Nanoparticles } & \multicolumn{7}{|c|}{ Time (hours) } \\
\hline & 2 & 24 & 48 & 72 & 96 & 168 & 216 \\
\hline \multirow[t]{2}{*}{ PLGA } & & & & & & & \\
\hline & 46.84 & 42.41 & 47.74 & 39.03 & 55.81 & 40.58 & 28.61 \\
\hline \multirow[t]{2}{*}{ PLGA + 5\% PVP } & & & & & & & \\
\hline & 54.28 & 27.28 & 31.91 & 20.92 & 25.49 & 25.28 & 8.51 \\
\hline \multirow{2}{*}{$\begin{array}{c}\mathrm{PLGA}+5 \% \mathrm{PVP}+5 \% \mathrm{PVP} \\
\text { co-polymer }\end{array}$} & & & & & & & \\
\hline & 47.80 & 40.83 & 51.00 & 32.04 & 20.04 & 29.22 & 16.70 \\
\hline
\end{tabular}

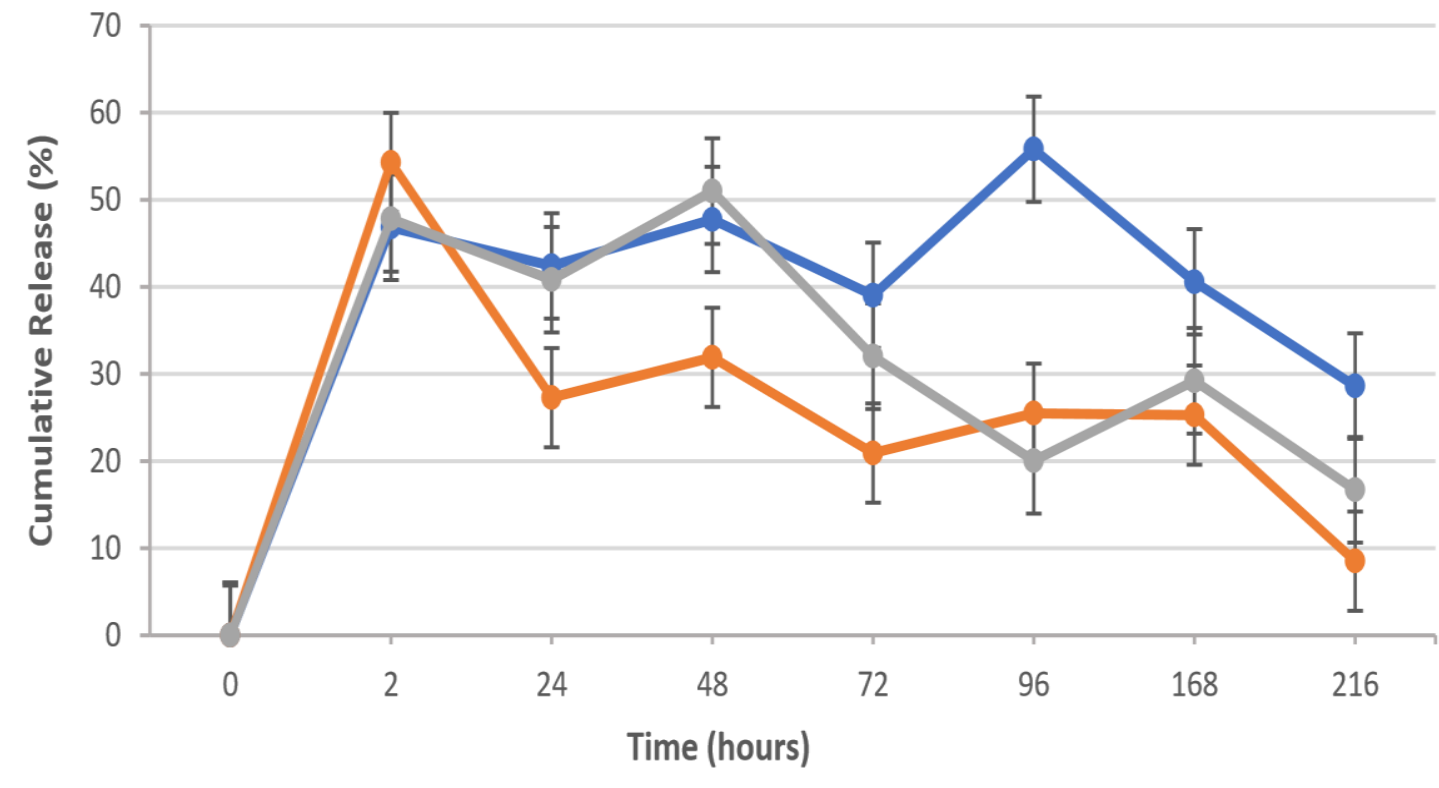

$\longrightarrow$ PLGA $\longrightarrow$ PLGA + 5\% PVP $\longrightarrow$ PLGA + 5\% PVP + 5\% PVP co-polymer

Figure 10: Release profileof various types of nanoparticles formulated by double emulsion/solvent evaporation technique 
DOI : https://dx.doi.org/10.26808/rs.aj.i8v1.02

American Journal of Sustainable Cities and Society

Issue 8, Vol. 1 January- December 2019

Available online on http://www.rspublication.com/ajscs/ajsas.html

ISSN $2319-7277$

Table 12: Rate of release at various time intervals for different types of nanoparticles formulated by microfluidics/salting out technique

\begin{tabular}{|c|c|c|c|c|c|c|c|}
\hline & & & & f Relea & & & \\
\hline \multirow[t]{2}{*}{ Type of Polymer } & \multicolumn{7}{|c|}{ Time (hours) } \\
\hline & 2 & 24 & 48 & 72 & 96 & 168 & 216 \\
\hline \multirow[t]{2}{*}{ PLGA } & & & & & & & \\
\hline & 15.68 & 5.81 & 25.41 & 23.31 & 17.21 & 24.84 & 7.40 \\
\hline \multirow[t]{2}{*}{ PLGA + 5\% PVP } & & & & & & & \\
\hline & 16.37 & 14.53 & 23.31 & 26.63 & 20.03 & 25.41 & 12.67 \\
\hline \multirow{2}{*}{$\begin{array}{c}\text { PLGA + 5\% PVP + 5\% } \\
\text { PVP co-polymer }\end{array}$} & & & & & & & \\
\hline & 37.34 & 28.87 & 37.76 & 25.98 & 24.27 & 27.96 & 24.10 \\
\hline
\end{tabular}

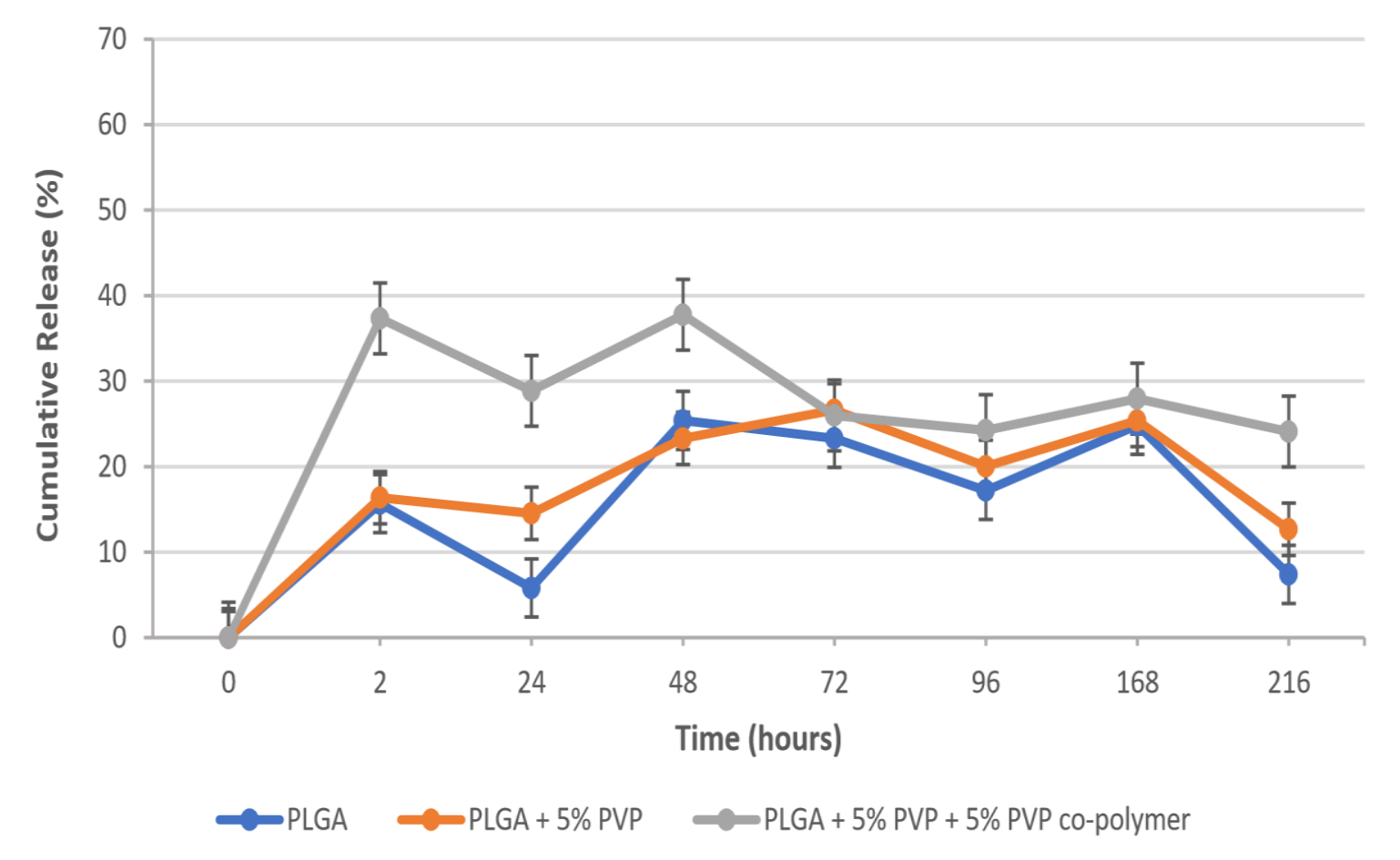

Figure 11: Release profile of various types of nanoparticles formulated by microfluidics/salting out technique

Insulin release was performed in vitro in PBS solution for 2, 24, 48, 72, 96, 168 and 216 hours whereby samples withdrawn were replaced with fresh PBS solution. The release profiles tabulated for both techniques were obtained by calculating the rate of release (\%) of 
nanoparticles of three different formulations at predetermined time intervals. Rate of release (\%) for each type of nanoparticles was calculated by using the concentration obtained from the equation of the calibration curve which was divided by the concentration obtained from insulin loading. Cumulative release $(\%)$ of nanoparticles for three different formulations was then calculated whereby compensation of the medium with fresh PBS solution was taken into consideration when calculations were made.

Overall, when compared with both of the techniques involved to formulate the nanoparticles of different formulations, nanoparticles formulated by double emulsion/solvent evaporation technique had the highest initial release than the nanoparticles formulated by microfluidics/salting out technique. However, PLGA + 5\% PVP nanoparticles and PLGA + $5 \%$ PVP $+5 \%$ PVP co-polymer nanoparticles of double emulsion/solvent evaporation technique had the lowest release at the final hour when compared to those nanoparticles of microfluidics/salting out technique. Also, the release at the final hour for PLGA nanoparticles of microfluidics/salting out technique was four times lower than that of double emulsion/solvent evaporation technique.

It is very important to study the in vitro release of drug in order to predict the drug bioavailability from various types of formulations. The rate of drug release is affected by the drug solubility, drug diffusion from the matrix of nanoparticle, expulsion of encapsulated drug, degradation of nanoparticles matrix and combination of diffusion/degradation process. Therefore, the release process depends on the solubility, biodegradation and dispersion of the matrix materials

(Nagal\&Singla, 2013). Drug release process is controlled by diffusion process when the drug is diffused earlier than the degradation of matrix. However, phenomenon such as burst release is often observed during the drug release process. Burst release, is the rapid release of drug initially before a stable release rate is achieved, which mainly caused by the drug which is bound on or near to the surface of the nanoparticles (Essa, Rabanel and Hildgen, 2010; Huang and Brazel, 2001).

For nanoparticles of double emulsion/solvent evaporation technique, the fast release of the drug in the beginning may be due to the burst release phase of the drug which caused by the drug that attached too close to the surface of the nanoparticles. This was followed by the slow drug release phase whereby drug is mainly diffused through the pores, channels of polymeric nanoparticles and degradation of the nanoparticle matrix occurs (El-Naggar et al., 2015). As soon as the drug is in contact with the medium, drug on the surface is released as a function of solubility. Generally, burst release of drug is affected by the type and concentration of drug as well as hydrophobicity of polymer (Huang and Brazel, 2001; Makadia and Siegel, 2011).

On the other hand, PLGA nanoparticles and PLGA + 5\% PVP nanoparticles of microfluidics/salting out technique showed low initial release rate and followed by slow nonconsistent release until the final hour. PLGA $+5 \%$ PVP $+5 \%$ PVP co-polymer nanoparticles showed higher initial release which lead to burst release of the drug. This indicates that microfluidics/salting out technique is effective to formulate nanoparticles with low initial release rate when compared to nanoparticles of double emulsion/solvent evaporation technique. However, a study performed by Hamishehkar et al. (2009) had revealed that polymer molecular weight can affect the burst release rate. Therefore, this study can be improved by investigating how formulation parameters such as polymer molecular weight and concentration can affect the release profiles of nanoparticles formulated by both of the techniques. 
DOI : https://dx.doi.org/10.26808/rs.aj.i8v1.02

American Journal of Sustainable Cities and Society

Issue 8, Vol. 1 January- December 2019

Available online on http://www.rspublication.com/ajscs/ajsas.html

ISSN $2319-7277$

\subsection{Compatibility and stability of insulin-loaded nanoparticles}

3.6.1. Fourier-transform infrared (FTIR) analysis
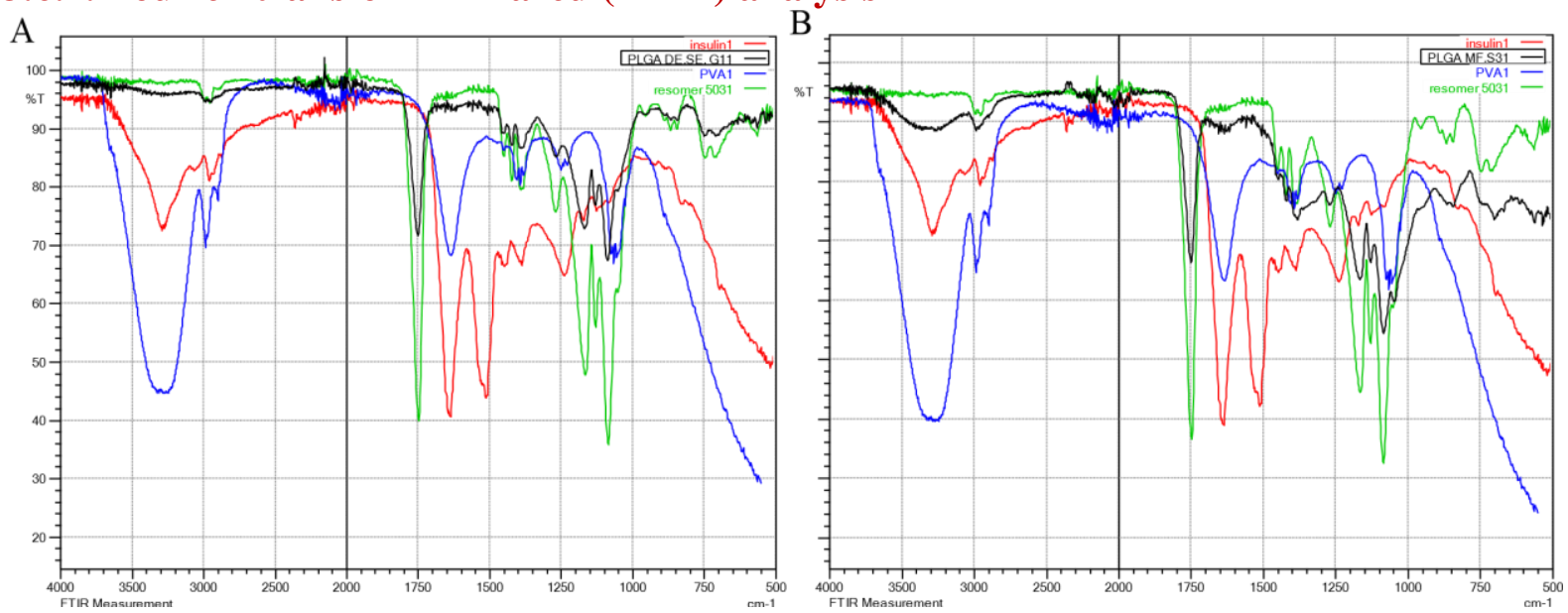

Figure 12: FTIR spectra of PLGA nanoparticles formulated by: (A) double emulsion/solvent evaporation technique; (B) microfluidics/salting out technique

A

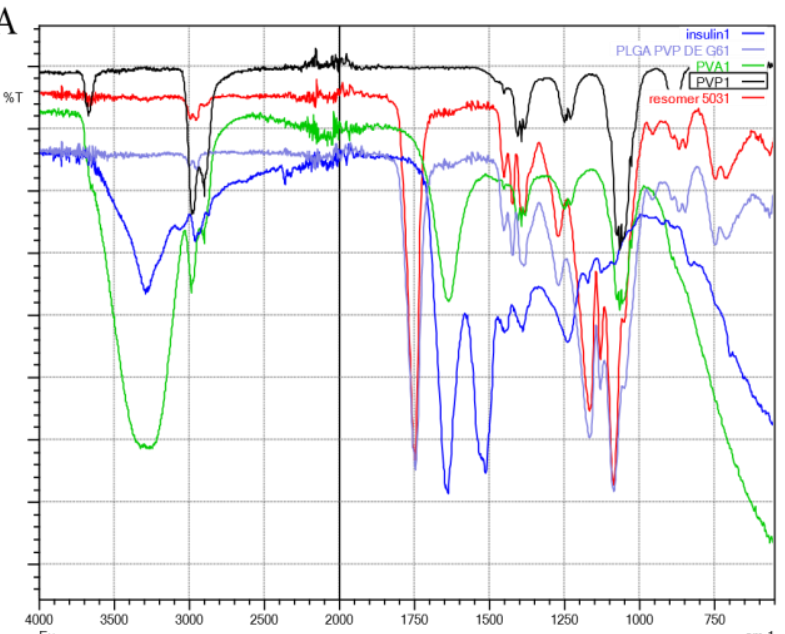

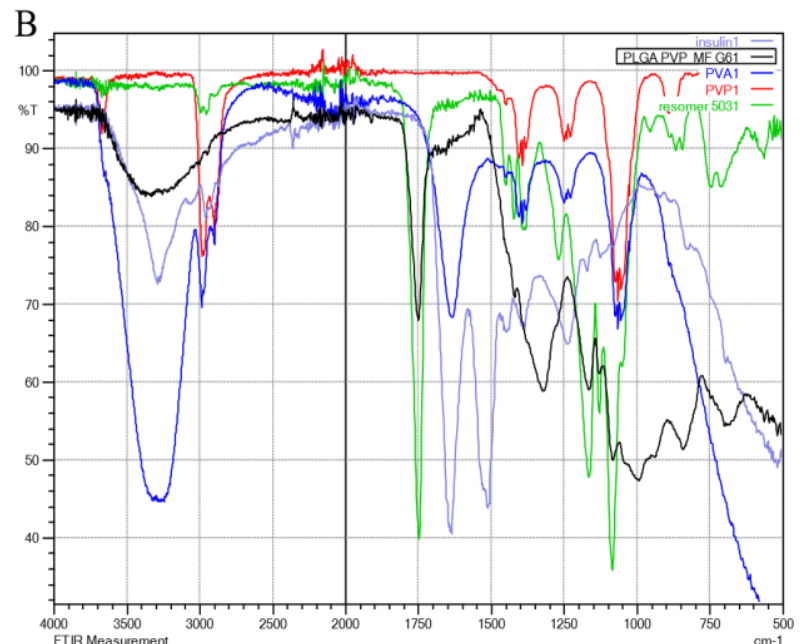

Figure 13: FTIR spectra of PLGA + 5\% PVP nanoparticles formulated by: (A) double emulsion/solvent evaporation technique; (B) microfluidics/salting out technique
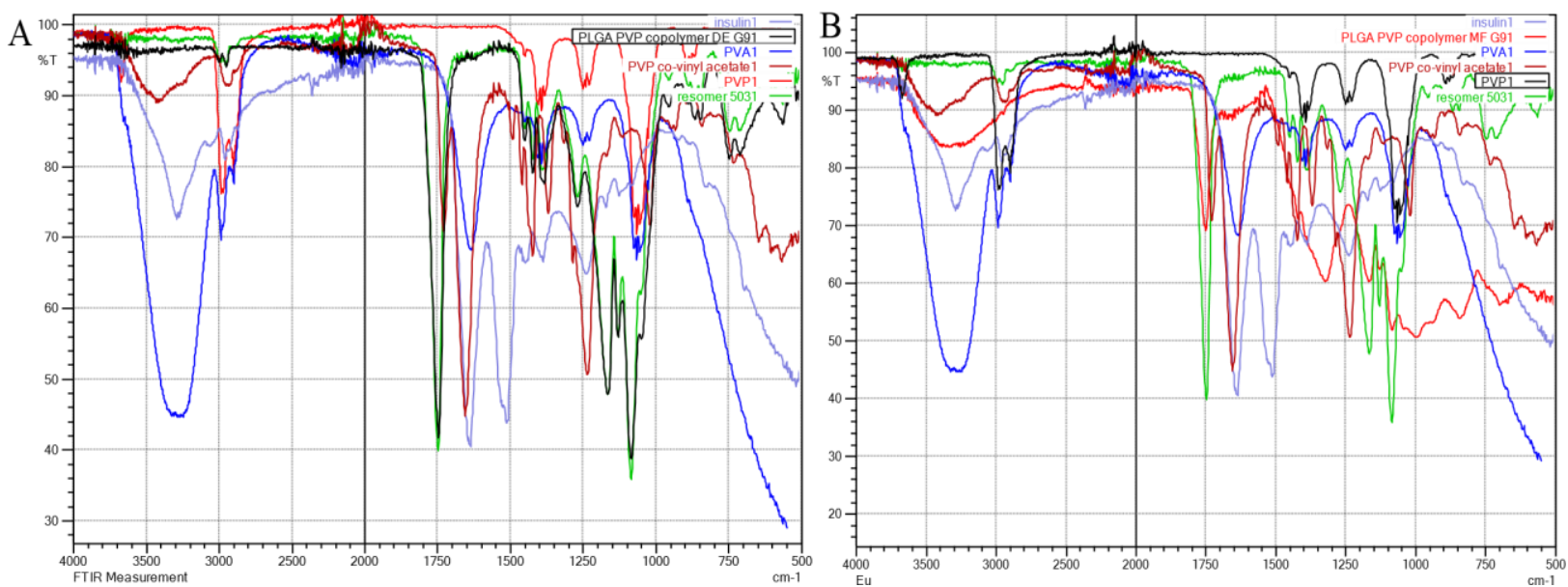

Figure 14: FTIR spectra of PLGA + 5\% PVP + 5\% PVP co-polymer nanoparticles formulated by: (A) double emulsion/solvent evaporation technique; (B) microfluidics/salting out technique 
As shown in Figure 12a and 12b, FTIR spectra of raw materials such as PVA, insulin and PLGA are presented together with the PLGA nanoparticles for both techniques. For the chart shown in Figure 13a and 13b, FTIR spectrum of raw material which is PVP was added to the previous raw materials spectra with the nanoparticles and PVP co-vinyl acetate was added in the chart shown in Figure 14a and 14b.

FTIR analysis was carried out in order to confirm the compatibility between PLGA polymer and insulin-loaded nanoparticles formulated in this study. FTIR is useful as different types of polymers used in this study exhibit different spectral fingerprints which can be used for comparison. To confirm the presence of insulin in the nanoparticles formulated, FTIR analysis of powder samples which include the raw materials used in the formulations of nanoparticles is performed where any changes in structures of polymers can be detected.

Based on the observations made on the FTIR analysis of nanoparticles, a strong band was observed at about $1750 \mathrm{~cm}^{-1}$ which indicates the $\mathrm{C}=\mathrm{O}$ stretching frequency of ester group. A band observed at about $3000 \mathrm{~cm}^{-1}$ which is assigned to $\mathrm{C}-\mathrm{H}$ stretching vibrations. Band observed in between $1000-1250 \mathrm{~cm}^{-1}$ are attributed to $\mathrm{C}-\mathrm{O}$ stretching vibration. The stretched band observed at about $1600 \mathrm{~cm}^{-1}$ is caused by the $\mathrm{C}=\mathrm{O}$ vibration for the primary amide band. Thus, the FTIR analysis obtained confirmed the presence of insulin in the nanoparticles. In addition, the FTIR analysis of nanoparticles resembled the PLGA polymer which indicates that insulin was encapsulated in the polymer as the interactions between PLGA and insulin can be observed (Saravanan, 2017). The disappearance of the peaks of other raw materials in the FTIR of nanoparticles formulated indicates that the materials were encapsulated in the insulin-loaded nanoparticles.

\subsubsection{Differential Scanning Calorimetry}
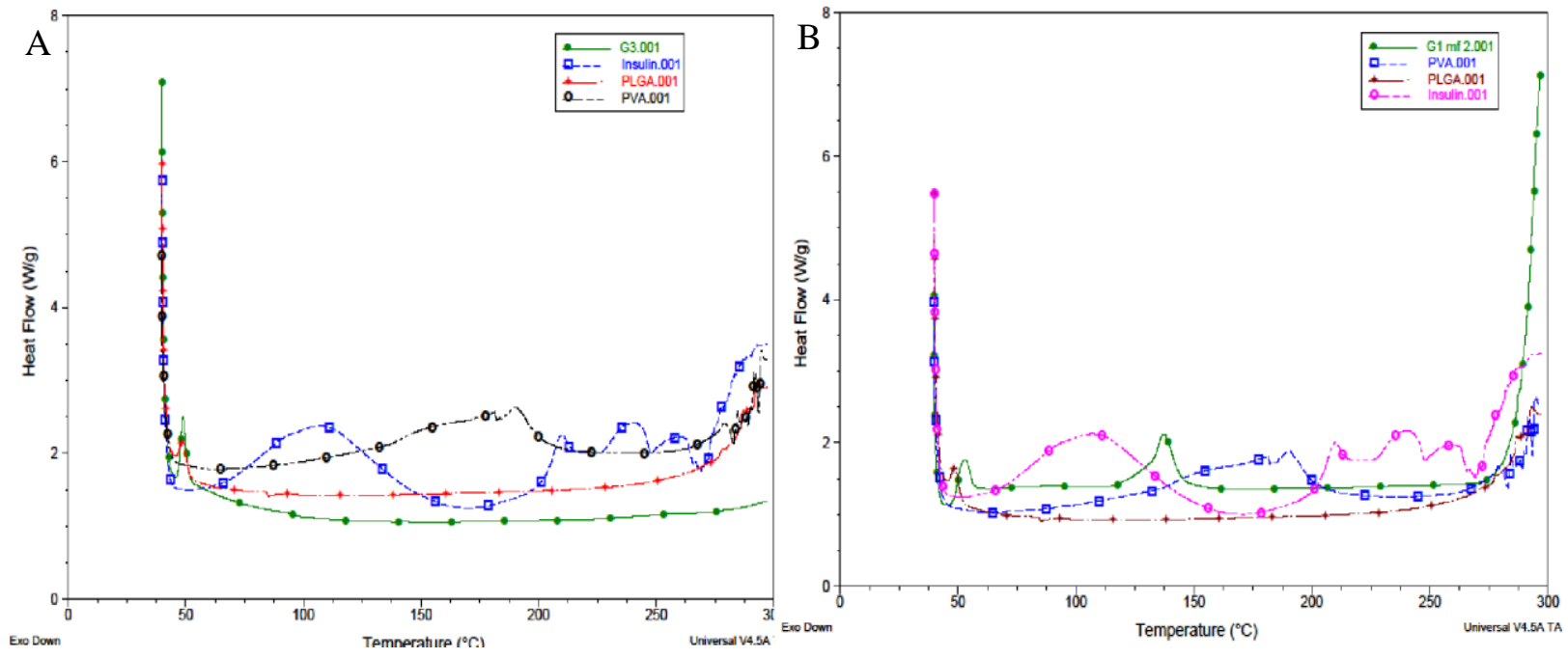

Figure 15: DSC thermograms of PLGA nanoparticles formulated by: (A) double emulsion/solvent evaporation technique; (B) microfluidics/salting out technique 

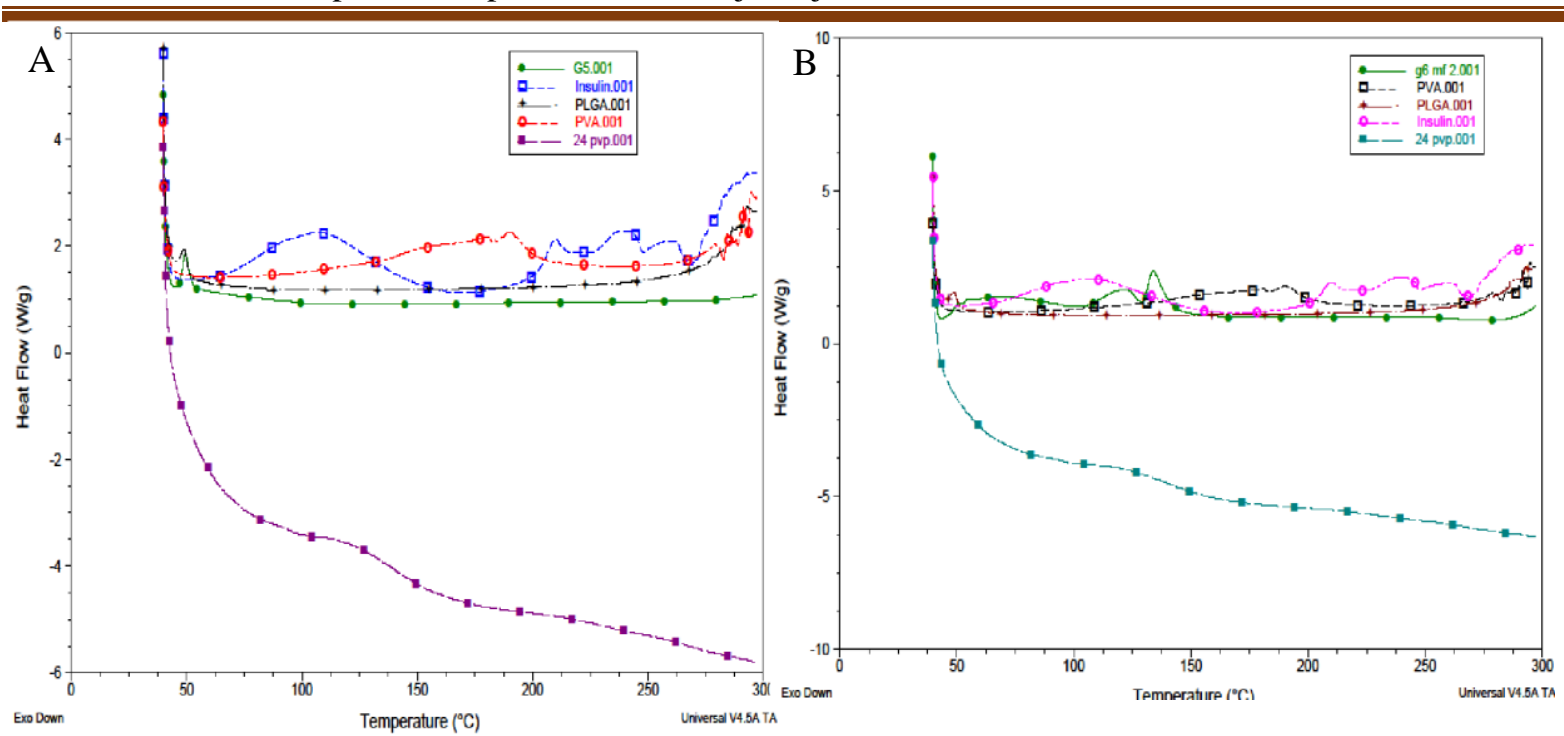

Figure 16: DSC thermograms of PLGA + 5\% PVP nanoparticles formulated by: (A) double emulsion/solvent evaporation technique; (B) microfluidics/salting out technique
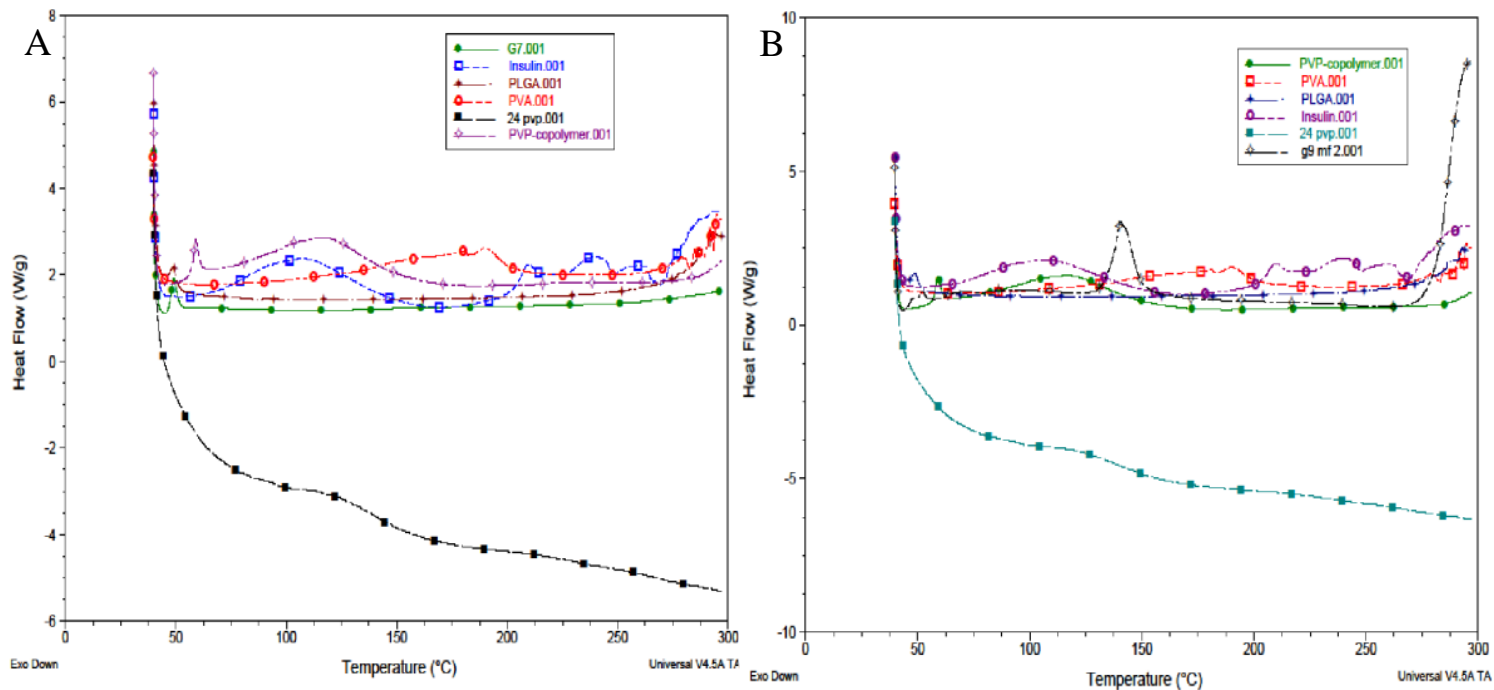

Figure 17: DSC thermograms of PLGA + 5\% PVP + 5\% PVP co-polymer nanoparticles formulated by: (A) double emulsion/solvent evaporation technique; (B) microfluidics/salting out technique

DSC was carried out to study the thermal behavior of insulin and polymers which is associated to their hydrophilic properties, structure and association state. In this technique, the heat capacity of the samples is used as a function of the temperature. In one test carried out, it is possible to get the complete profile of temperature of the Gibbs energy change which is correlated with the loss of water in polymers. Also, denaturation process of proteins and depolymerization can be obtained at high temperatures. Based on a DSC thermogram, interactions between polymers and drugs can be deduced from the modifications of exothermic and endothermic peaks (Sarmento et al., 2006). As shown in the thermograms (Figure 15-17), raw materials of the nanoparticles were also analyzed according to the materials used in the formulations of the nanoparticles for comparison of the results.

Based on the thermograms obtained, the thermogram of insulin showed a broad endothermic peak at about $100^{\circ} \mathrm{C}$ and several endothermic peaks above $200^{\circ} \mathrm{C} . \mathrm{h}$ However, for 
comparison, the thermogram of insulin in a study done by Hamishehkar et al. (2009) showed two endothermic peaks at about $61^{\circ} \mathrm{C}$ and $91^{\circ} \mathrm{C}$. In the present study, the broad endothermic peak shown is probably caused by the combination of two peaks into one which results in one broad peak. Generally, the drug that entrapped in the insulin-loaded nanoparticles is usually in a crystalline state. When compared to the amorphous form, crystalline proteins are less affected by chemical degradation. A lattice structure with the protein molecule can be formed as a result of crystallization of protein. Thus, the loss of biological activity can be minimized as direct interaction among protein molecules is fairly weak in most crystals (Hamishehkar et al., 2009).

In order to determine the physical strength of the polymeric delivery systems, glass transition temperature (Tg) is an essential factor. Based on the thermograms of PLGA polymer, the Tg of PLGA was at about $50^{\circ} \mathrm{C}$. This indicates that the Tg of PLGA is above the physiological temperature which makes the polymer to provide adequate strength for drug delivery systems. On the other hand, it is observed that the Tg of insulin-loaded nanoparticles for both of the technique is about $50^{\circ} \mathrm{C}$. The Tg of insulin-loaded nanoparticles is about the same as the $\mathrm{Tg}$ of PLGA polymer which means that the insulin is entrapped in the polymer. However, another endothermic peak at about $140^{\circ} \mathrm{C}$ was observed for insulin-loaded nanoparticles of microfluidics technique. The presence of endothermic peaks in these insulin-loaded nanoparticles were probably due to loss of water affected by hydrophilic groups of polymers or insulin denaturation which is caused by modification in the conformation of the protein chains in the structure. Usually, decomposition of insulin takes place in between $200^{\circ} \mathrm{C}$ and $300^{\circ} \mathrm{C}$ (Mimi et al., 2015; Sarmento et al., 2006).

For improvement, DSC for insulin should be repeated as the thermogram of insulin obtained showed broad endothermic peak. Other than that, DSC for unloaded nanoparticles should be carried out as well in order to make comparison with insulin-loaded nanoparticles.

\section{Conclusion}

Polymeric insulin-loaded nanoparticles were successfully formulated by using double emulsion/solvent evaporation method which involves homogenization and microfluidics/salting out technique. The aim of the study was achieved as the physicochemical characteristics of the insulin-loaded nanoparticles formulated by two different techniques were compared. Apart from that, formulation parameter such as type of polymer had shown to affect the physicochemical characteristics of the insulin-loaded nanoparticles in this study. The size of nanoparticles formulated ranged from 270 to $390 \mathrm{~nm}$ for both of the techniques which had shown PLGA nanoparticles to be the largest among all the type of nanoparticles. Insulin-loaded nanoparticles formulated were spherical and negatively charged where nanoparticles formulated by microfluidics/salting out technique had shown higher negative zeta potential than nanoparticles formulated by double emulsion/solvent evaporation technique. Entrapment efficiency of nanoparticles was higher for nanoparticles formulated by double emulsion/solvent evaporation technique whereas nanoparticles formulated by microfluidics/salting out technique showed different results than nanoparticles of double emulsion/solvent evaporation method and the difference in the results were discussed. Insulin-loaded nanoparticles showed higher initial release during insulin in vitro release study when compared to nanoparticles formulated by microfluidic/salting out technique whereby the latter technique is preferred for insulin in vitro release study. FTIR and DSC were carried out to investigate the compatibility and stability of insulin-loaded nanoparticles formulated by both of the techniques.

Thus, the results showed that formulation or preparation techniques of nanoparticles in this study have affected the physicochemical characteristics of the insulin-loaded nanoparticles. 
Polymeric insulin-loaded nanoparticles had shown promising results in numerous studies related to insulin delivery. Microfluidics/salting out technique which was the novel technique in this study had shown formulation of effective insulin-loaded nanoparticles. Therefore, for future approach, this study should be a platform or the starting point to study extensively regarding insulin-loaded nanoparticles formulated with both of the techniques used with the improvements discussed or suggested.

\section{References}

1. Bakhru, S., Furtado, S., Morello, A. and Mathiowitz, E. (2013). Oral delivery of proteins by biodegradable nanoparticles. Advanced Drug Delivery Reviews, 65(6), pp.811-821.

2. Chen, M., Sonaje, K., Chen, K. and Sung, H. (2011). A review of the prospects for polymeric nanoparticle platforms in oral insulin delivery. Biomaterials, 32(36), pp.98269838.

3. Cui, F., Shi, K., Zhang, L., Tao, A. and Kawashima, Y. (2006). Biodegradable nanoparticles loaded with insulin-phospholipid complex for oral delivery: Preparation, in vitro characterization and in vivo evaluation. Journal of Controlled Release, 114(2), pp.242-250.

4. Díaz, M. and Vivas-Mejia, P. (2013). Nanoparticles as Drug Delivery Systems in Cancer Medicine: Emphasis on RNAi-Containing Nanoliposomes. Pharmaceuticals, 6(11), pp.13611380.

5. El-Naggar, M., El-Rafie, M., El-sheikh, M., El-Feky, G. and Hebeish, A. (2015). Synthesis, characterization, release kinetics and toxicity profile of drug-loaded starch nanoparticles. International Journal of Biological Macromolecules, 81, pp.718-729.

6. Essa, S., Rabanel, J. and Hildgen, P. (2010). Effect of polyethylene glycol (PEG) chain organization on the physicochemical properties of poly(d, l-lactide) (PLA) based nanoparticles. European Journal of Pharmaceutics and Biopharmaceutics, 75(2), pp.96106.

7. Fonte, P., Soares, S., Costa, A., Andrade, J., Seabra, V., Reis, S. and Sarmento, B. (2012). Effect of cryoprotectants on the porosity and stability of insulin-loaded PLGA nanoparticles after freezedrying. Biomatter, 2(4), pp.329-339.

8. Gupta, R. and Mohanty, S. (2017). Controlled release of insulin from folic acid-insulin complex nanoparticles. Colloids and Surfaces B: Biointerfaces, 154, pp.48-54.

9. Haggag, Y., Abdel-Wahab, Y., Ojo, O., Osman, M., El-Gizawy, S., El-Tanani, M., Faheem, A. and McCarron, P. (2016). Preparation and in vivo evaluation of insulinloaded biodegradable nanoparticles prepared from diblock copolymers of PLGA and PEG. International Journal of Pharmaceutics, 499(1-2), pp.236-246.

10. Hamishehkar, H., Emami, J., Najafabadi, A., Gilani, K., Minaiyan, M., Mahdavi, H. and Nokhodchi, A. (2009). The effect of formulation variables on the characteristics of insulin-loaded poly(lactic-co-glycolic acid) microspheres prepared by a single phase oil in oil solvent evaporation method. Colloids and Surfaces B: Biointerfaces, 74(1), pp.340349.

11. He, C., Hu, Y., Yin, L., Tang, C. and Yin, C. (2010). Effects of particle size and surface charge on cellular uptake and biodistribution of polymeric nanoparticles. Biomaterials, 31(13), pp.36573666.

12. Honary, S., Jahanshahi, M., Golbayani, P., Ebrahimi, P. and Ghajar, K. (2010). DoxorubicinLoaded Albumin Nanoparticles: Formulation and Characterization. Journal of Nanoscience and Nanotechnology, 10(11), pp.7752-7757. 
13. Huang, X. and Brazel, C. (2001). On the importance and mechanisms of burst release in matrixcontrolled drug delivery systems. Journal of Controlled Release, 73(2-3), pp.121136.

14. Izu, N., Uchida, T., Matsubara, I., Itoh, T., Shin, W. and Nishibori, M. (2011). Formation mechanism of monodispersed spherical core-shell ceria/polymer hybrid nanoparticles. Materials Research Bulletin, 46(8), pp.1168-1176.

15. Keohane, K., Brennan, D., Galvin, P. and Griffin, B. (2014). Silicon microfluidic flow focusing devices for the production of size-controlled PLGA based drug loaded microparticles. International Journal of Pharmaceutics, 467(1-2), pp.60-69.

16. Kumar, B., Jalodia, K., Kumar, P. and Gautam, H. (2017). Recent advances in nanoparticlemediated drug delivery. Journal of Drug Delivery Science and Technology, 41, pp.260-268.

17. Li, J., Inukai, K., Takahashi, Y., Tsuruta, A. and Shin, W. (2017). Effect of PVP on the synthesis of high-dispersion core-shell barium-titanate-polyvinylpyrrolidone nanoparticles. Journal of Asian Ceramic Societies, 5(2), pp.216-225.

18. Lu, Z., Bei, J. and Wang, S. (1999). A method for the preparation of polymeric nanocapsules without stabilizer. Journal of Controlled Release, 61(1-2), pp.107-112.

19. Makadia, H. and Siegel, S. (2011). Poly Lactic-co-Glycolic Acid (PLGA) as Biodegradable Controlled Drug Delivery Carrier. Polymers, 3(4), pp.1377-1397.

20. Mimi, N., Belkacemi, H., Sadoun, T., Sapin, A. and Maincent, P. (2015). How the composition and manufacturing parameters affect insulin release from polymeric nanoparticles. Journal of Drug Delivery Science and Technology, 30, pp.458-466.

21. Moinard-Chécot, D., Chevalier, Y., Briançon, S., Beney, L. and Fessi, H. (2008). Mechanism of nanocapsules formation by the emulsion-diffusion process. Journal of Colloid and Interface Science, 317(2), pp.458-468.

22. Mora-Huertas, C., Fessi, H. and Elaissari, A. (2010). Polymer-based nanocapsules for drug delivery. International Journal of Pharmaceutics, 385(1-2), pp.113-142.

23. Mora-Huertas, C., Garrigues, O., Fessi, H. and Elaissari, A. (2012). Nanocapsules prepared via nanoprecipitation and emulsification-diffusion methods: Comparative study. European Journal of Pharmaceutics and Biopharmaceutics, 80(1), pp.235-239.

24. Nagal, A and Singla, R.K. (2013). Nanoparticles in different delivery systems: a brief review. Indo Global Journal of Pharmaceutical Sciences, 3, pp.96-106.

25. Panyam, J. and Labhasetwar, V. (2012). Biodegradable nanoparticles for drug and gene delivery to cells and tissue. Advanced Drug Delivery Reviews, 64, pp.61-71.

26. Perez, A., Hernández, R., Velasco, D., Voicu, D. and Mijangos, C. (2015). Poly (lacticco-glycolic acid) particles prepared by microfluidics and conventional methods. Modulated particle size and rheology. Journal of Colloid and Interface Science, 441, pp.90-97.

27. Rizkalla, N., Range, C., Lacasse, F. and Hildgen, P. (2006). Effect of various formulation parameters on the properties of polymeric nanoparticles prepared by multiple emulsion method. Journal of Microencapsulation, 23(1), pp.39-57.

28. Saravanan, S., Malathi, S., Sesh, P.S.L., Selvasubramanian, S., Balasubramanian, S. and Pandiyan, V. (2017). Hydrophilic poly (ethylene glycol) capped poly (lactic-co-glycolic) acid nanoparticles for subcutaneous delivery of insulin in diabetic rats. International Journal of Biological Macromolecules, 95, pp.1190-1198.

29. Sarmento, B., Ferreira, D., Veiga, F. and Ribeiro, A. (2006). Characterization of insulinloaded alginate nanoparticles produced by ionotropic pre-gelation through DSC and FTIR studies. Carbohydrate Polymers, 66(1), pp.1-7. 
30. Sawant, K. and Dodiya, S. (2008). Recent Advances and Patents on Solid Lipid Nanoparticles. Recent Patents on Drug Delivery \& Formulation, 2(2), pp.120-135.

31. Sharma, G., Sharma, A., Nam, J., Doss, G., Lee, S. and Chakraborty, C. (2015). Nanoparticle based insulin delivery system: the next generation efficient therapy for Type 1 diabetes. Journal of Nanobiotechnology, 13(1).

32. Vladisavljević, G., Shahmohamadi, H., Das, D., Ekanem, E., Tauanov, Z. and Sharma, L. (2014). Glass capillary microfluidics for production of monodispersed poly (dl-lactic acid) and polycaprolactonemicroparticles: Experiments and numerical simulations. Journal of Colloid and Interface Science, 418, pp.163-170.

33. Yu, F., Li, Y., Liu, C., Chen, Q., Wang, G., Guo, W., Wu, X., Li, D., Wu, W. and Chen, X. (2015). Enteric-coated capsules filled with mono-disperse micro-particles containing PLGA-lipid-PEG nanoparticles for oral delivery of insulin. International Journal of Pharmaceutics, 484(1-2), pp.181-191.

34. Yu, M., Wu, J., Shi, J. and Farokhzad, O. (2016). Nanotechnology for protein delivery: Overview and perspectives. Journal of Controlled Release, 240, pp.24-37.

35. Zhu, K. J., Jiang, H. L., Du, X. Y., Wang, J., Xu, W. X. AND Liu, S. F. (2001). Preparation and characterization of hCG-loaded polylactide or poly(lactide-co-glycolide) microspheres using a modified water-in-oil-in-water (w/o/w) emulsion solvent evaporation technique. Journal of Microencapsulation, 18(2), pp.247-260. 